This item was submitted to Loughborough's Research Repository by the author.

Items in Figshare are protected by copyright, with all rights reserved, unless otherwise indicated.

\title{
A review of split-cycle engines
}

PLEASE CITE THE PUBLISHED VERSION

https://doi.org/10.1177/1468087418789528

PUBLISHER

SAGE (@ IMechE)

VERSION

AM (Accepted Manuscript)

PUBLISHER STATEMENT

This work is made available according to the conditions of the Creative Commons Attribution-NonCommercialNoDerivatives 4.0 International (CC BY-NC-ND 4.0) licence. Full details of this licence are available at: https://creativecommons.org/licenses/by-nc-nd/4.0/

\section{LICENCE}

CC BY-NC-ND 4.0

\section{REPOSITORY RECORD}

Finneran, Joshua, Colin P. Garner, M.D. Bassett, and Jonathan Hall. 2019. "A Review of Split-cycle Engines". figshare. https://hdl.handle.net/2134/34814. 


\title{
A Review of Split-Cycle Engines
}

\author{
Joshua Finneran ${ }^{1 *}$, Colin P Garner ${ }^{1}$, Michael Bassett ${ }^{2}$ and Jonathan Hall ${ }^{2}$ \\ ${ }^{1}$ Loughborough University, UK. \\ ${ }^{2}$ MAHLE Powertrain, Ltd. UK.
}

\begin{abstract}
This paper reviews split-cycle internal combustion (IC) engine designs. The review includes historical work, assessment of prototypes and discussion of the most recent designs. There has been an abundance of split-cycle engine designs proposed since the first in 1872. Despite this, very few prototypes exist, and no split-cycle engines are reported to be in series production. The few split-cycle prototypes that have been developed have faced practical challenges contributing to limited performance. These challenges include air flow restrictions into the expansion cylinder, late combustion, thermal management issues, and mechanical challenges with the crossover valve actuation mechanism. The main promoted advantage of split-cycle engines is the increased thermal efficiency compared to conventional IC engines. However, an efficiency improvement has not thus far been demonstrated in published test data. The thermodynamic studies reviewed suggest that split-cycle engines should be more efficient than conventional four-stroke engines. Reasons why increased thermal efficiency is not realised in practice could be due to practical compromises, or due to inherent architectural split-cycle engine design limitations. It was found that the number of split-cycle engine patents has increased significantly over recent years, suggesting an increased commercial interest in the concept since the possibility of increased efficiency becomes more desirable and might outweigh the drawbacks of practical challenges.
\end{abstract}

Keywords: Split Cycle, Split Combustion, Internal Combustion, Engine, Review, Divided, Heat Recovery, Efficiency, Emissions, Expander.

Accepted $19^{\text {th }}$ June 2018

"Corresponding author: Joshua Finneran, Wolfson School of Mechanical, Electrical and Manufacturing Engineering, Loughborough University, UK. j.finneran@lboro.ac.uk 


\section{Introduction}

With ever growing concern over fossil fuel depletion and environmental damage from engine emissions, there are increased pressures on manufacturers to produce cleaner, more efficient engines. This has driven an increased desire to investigate alternative engine concepts. One such concept is the split-cycle engine.

The term 'Split-Cycle Engine' refers to a type of IC engine where the conventional fourstroke cycle is executed over two cylinders. The intake and compression strokes take place in a first cylinder. The compressed gas is then delivered to a second cylinder where the expansion and exhaust strokes take place.

Split-cycle engines are of interest because they potentially possess distinct advantages over the widely used conventional four-stroke engine. The act of splitting the cycle over two cylinders opens up a variety of possibilities that are not achievable if the cycle is contained within one cylinder. These possibilities include using exhaust heat recovery to add heat at the end of the compression stroke, e.g. between the cylinders, as well as using a different compression ratio to expansion ratio. By utilizing these factors, as well as others, it is postulated by some authors that the split-cycle could exceed the performance of a conventional engine in terms of thermal efficiency. Other potential benefits include reduced emissions compared to conventional engines. Contained within this paper is a review of existing work relating to split-cycle engines. The aim of this paper is to assess split-cycle engine designs and prototypes within the context of their efficiency and emissions, which are key primary drivers for engine design in today's environment. Special attention is also paid to practical challenges associated with the design of split-cycle engines. The first section presents an overview of split-cycle engine operation. Following this, historical split-cycle designs are presented and discussed. The existing prototypes and accompanying test data are reviewed, along with the corresponding claims about the various engines considered. The paper continues with a discussion of the most recent split-cycle engine designs, which indicates the possible future for split-cycle engine development. The paper concludes with a discussion of other simulation work on split-cycle operation and a summary of the various claims made regarding split-cycle engines. 


\section{Split-Cycle Engine Overview}

A split-cycle engine is a type of IC engine in which the processes of a four-stroke cycle are performed over two separate cylinders. The intake and compression strokes are performed in a first cylinder, usually referred to as the compressor. The expansion and exhaust strokes are performed in a second cylinder, usually referred to as the expander. The means by which the two cylinders communicate may vary between different engine designs.

The earliest found design of a split-cycle engine was the reciprocating Gas Engine, made in 1872 by George Brayton [1], and is discussed later. In 1906 the 'Dolphin engine', as shown in Figure 1, was built by Harry Ricardo [2] and was used in marine applications. However, at this time the term 'split-cycle' was not used, instead the invention was said to operate a two-stroke cycle. The earliest found use of the term 'split-cycle' is from 1957 to describe an invention by Robert Black [3]. Following this, many still referred to these types of engines in other ways, such as 'split-combustion engines' or 'two-stroke regenerative cycles' [4]. Today, the term split-cycle is widely used to categorise this type of engine after popularisation of the term, for example by the Scuderi Group [5].

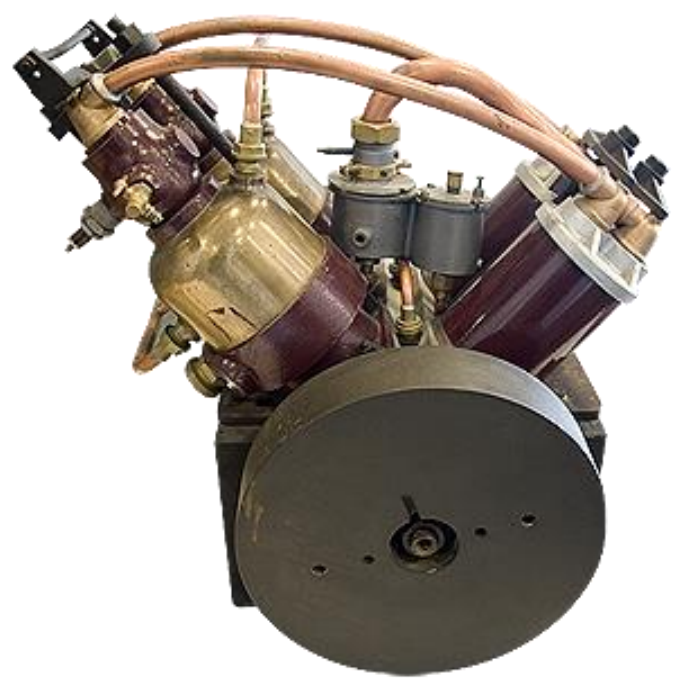

Figure 1 Ricardo Dolphin Engine (Photograph used with permission of Ricardo UK Ltd)

A typical split-cycle engine is shown schematically in Figure 2. Many similarities exist between split-cycle engines and other engines or cycles. A split-cycle engine has a 'hot' and a 'cold' cylinder, similar to a Stirling engine. However, split-cycle engines are internal combustion engines whereas the heat is applied externally to a Stirling engine. Given this definition, another example of a split-cycle engine around the time of 
Brayton would be Hirsch's engine, 1874 [6]. However, the bulk of the working fluid is passed straight through a split-cycle engine such that it operates an open cycle, which distinguishes them from closed cycle Stirling-type engines. For the purposes of this review, a split-cycle engine is defined as an IC engine in which compression and expansion take place in separate piston-cylinder devices, and which operates an open cycle as in conventional IC engines.

For this reason, the split-cycle is comparable to Brayton cycle engines such as the gas turbine, in which compression and expansion take place in separate devices, with combustion taking place between. The split-cycle differs in that piston-cylinder devices are used rather than turbomachinery and thus can have higher compression/ expansion ratios without need for multiple stages. Additionally, combustion in a splitcycle engine is intermittent and takes place in a confined volume meaning higher peak temperatures can be tolerated and combustion does not necessarily take place at constant pressure as in the thermodynamic Brayton cycle.

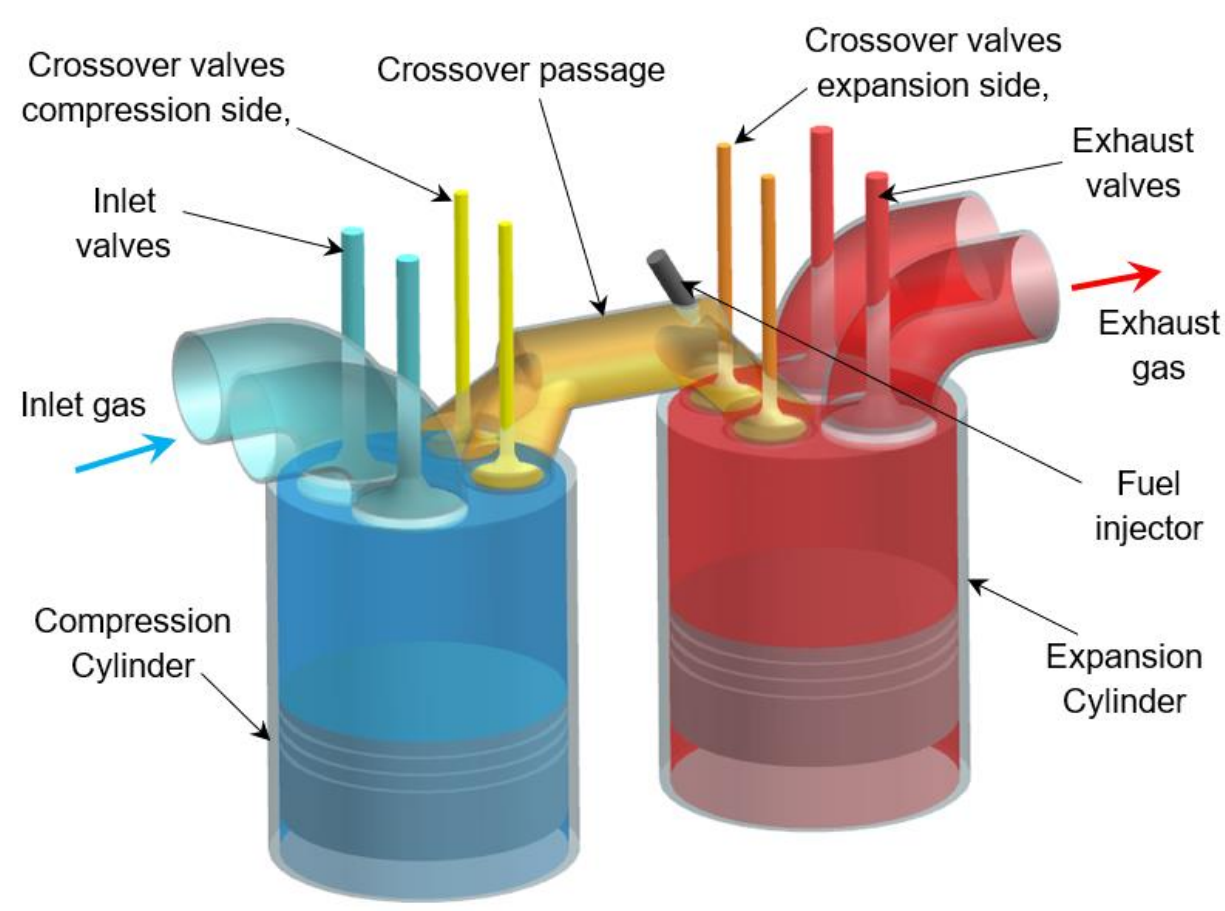

Figure 2 Schematic of a Split-cycle Engine

In order to provide context to the discussion of the various engine designs considered in this review, the basic operating stages of the split-cycle will now be outlined. The stages of the cycle are depicted in Figure 3 and are considered as:

1. Fresh charge is inducted into the compression cylinder; 
2. Charge is compressed in the compression cylinder. Near the top of the compression stroke, the first crossover valve opens allowing the compressed charge to be passed into the crossover passage;

3. The second crossover valve opens when the expansion piston is near top dead centre (TDC) to allow the pre-compressed charge into the expansion cylinder;

4. Combustion is initiated some duration after TDC in the expansion cylinder. The combustion event may, or may not, overlap with the crossover valve opening time (stage 3). The combustion event forces the expansion piston down producing useful work as the gas is expanded;

5. The exhaust valve opens when the expansion piston is near bottom dead centre (BDC) and the combustion gases are expelled from the cylinder as the expansion piston returns towards TDC.

In some early designs of split-cycle engines combustion was meant to occur in the crossover passage. However, no prototype engines of this combustion method are known to exist. This is probably due to practical constraints because of thermal loading issues.

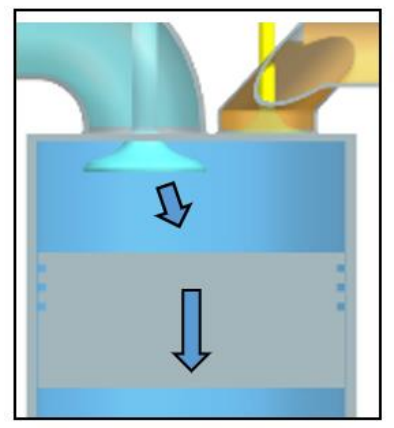

(1) Intake

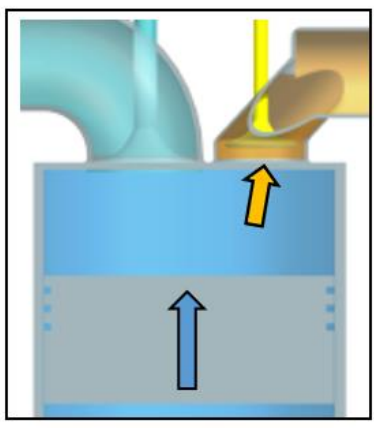

(2) Transfer, compressor side

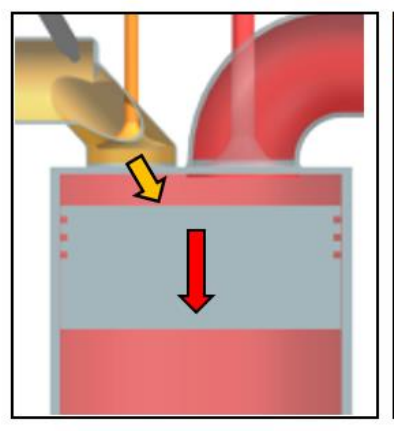

(3/4) Transfer, expander side and combustion

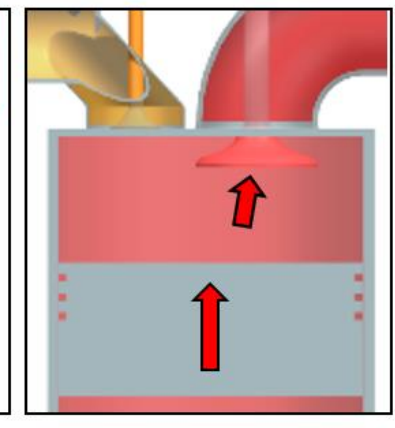

(5) Exhaust

Figure 3 Stages in a Split-cycle

A split-cycle has added flexibility over a conventional four-stroke engine since the cycle events are not bound to one cylinder. This added flexibility allows utilisation of the features listed below to possibly increase performance compared to a four-stroke [7]. The potential benefits of these effects compared to alternatives are shown in Figure 4.

1. Reduced compression work by cooling the compression cylinder; 
2. Miller-cycle type operation by relative sizing of cylinders optimising compression ratio and expansion ratio;

3. Recovery of exhaust gas heat between the two cylinders, as depicted in Figure 5.

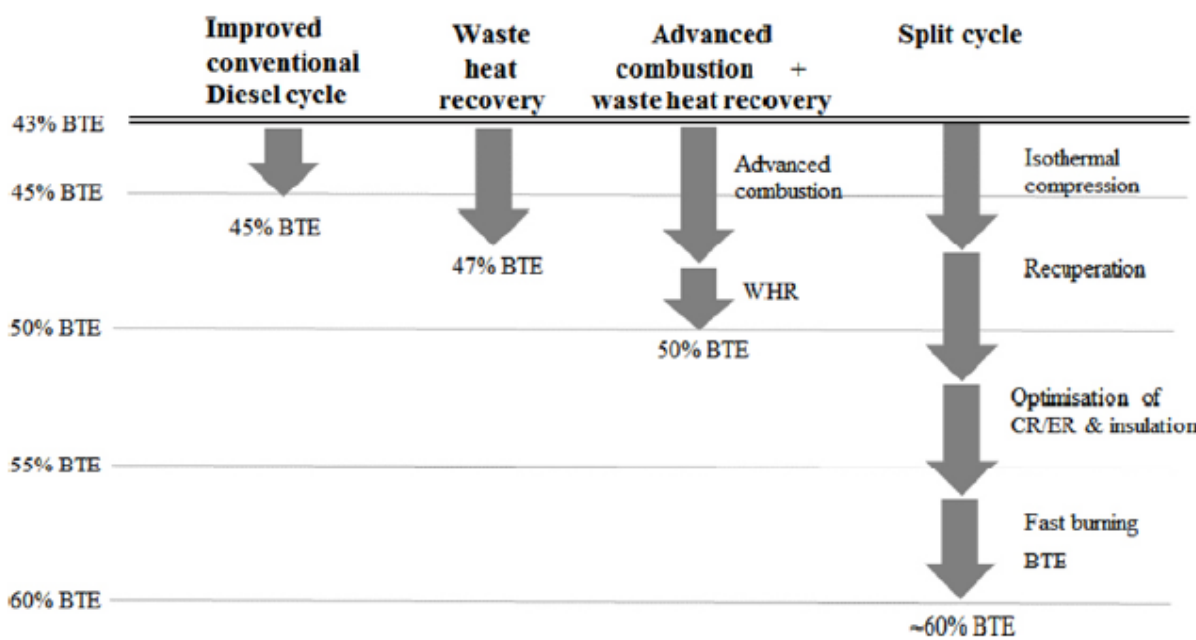

Figure 4 Incremental potential brake thermal efficiency improvement of various engine technologies [8]

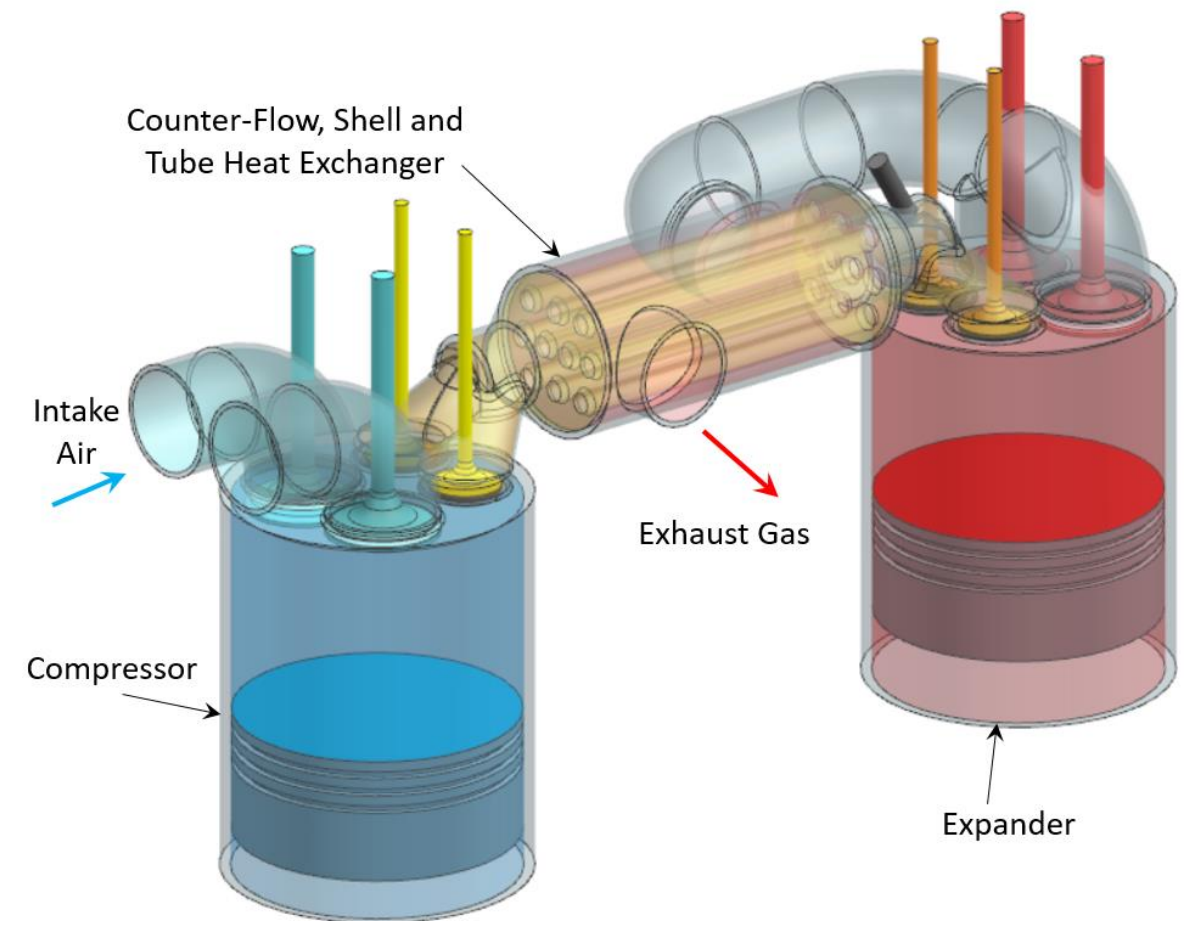

Figure 5 Example of Exhaust Heat Recovery Implementation on a Split-cycle Engine 


\section{Split-cycle Engine Designs from History}

A significant number of split-cycle designs have been proposed since the first from 1872. In this review the key examples are selected for discussion. Attention has been paid to design features that are unique to split-cycle engines and the discussion focusses on the various claims made about the split-cycle engine.

Firstly, Brayton's reciprocating gas engine will now be discussed [1]. Although now associated with gas turbines, Brayton's efforts concerned reciprocating piston engines. His gas engine design is shown in Figure 6. This design differs from all others discussed in that it is double acting, meaning the compressor and expander are on opposite sides of the same cylinder. Air and gas are drawn into the compressor, then the compressed mixture is delivered to the pressure reservoir. It can be seen that the pressure reservoir, which in this case is the crossover passage, is large relative to the cylinder volumes. In some recent split-cycle designs the crossover passage volume is claimed to be an important parameter, as discussed later. The compressed fuel and air mixture is drawn into the expander past a constant flame jet where it is ignited. Wire meshes were used to try and prevent the flame from propagating back through the pressure reservoir. Combustion occurred at (near) constant pressure at a pressure below that of the reservoir, with the crossover valve open. The combustion products expanded once the crossover expander inlet valve had closed. While using gaseous fuel the engine suffered from backfiring so future engines used liquid fuels that were added as the mixture flowed into the expander. Many of the Brayton engines built were of the two-cylinder single acting type, not double acting as shown in Figure 6. The engine was hindered by low compression ratios, excessive throttling losses, and low mechanical efficiency. This resulted in a thermal efficiency around $7 \%$ which meant it was unable to compete with Otto's four-stroke engine that emerged a few years later [1]. 


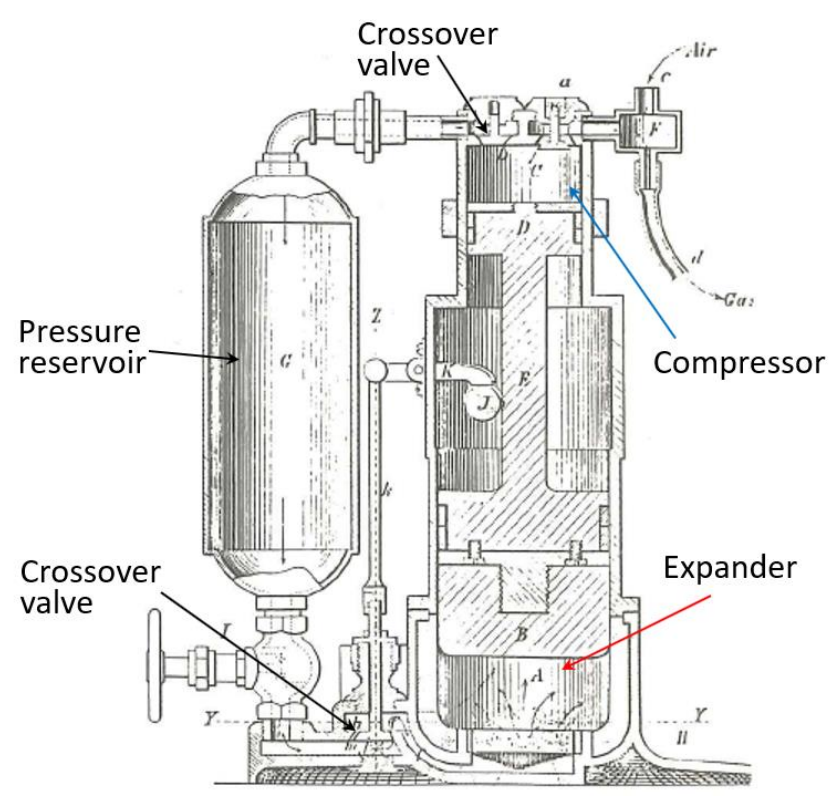

Figure 6 Brayton's gas engine, 1872 [1], originally from Brayton's British patent. (annotations added)

Webb's 1913 split-cycle engine [9], shown in Figure 7, consists of two cylinders, a compressor and expander, connected via a crossover passage. This is the most fundamental design of a split-cycle engine.

A phase angle is included between the cylinders such that the expander leads the compressor by about 45 degrees of crankshaft rotation. In Figure 7 the compression piston is shown to be travelling up, while the expansion piston is beginning its descent. In this particular design, combustion occurs in the crossover passage, which then expands in the expansion cylinder. This implies that the crossover passage would need to be suitably sized such that there is not an excessive amount of residual combustion gases remaining in the passage prior to the next cycle.

Interestingly, the expansion cylinder is larger than the compression cylinder. Whilst the reasoning for this is not given in the description of the design, it highlights one of the potential advantages of split-cycle operation. Unlike a four-stroke engine, the expansion ratio can be larger than the compression ratio to give a Miller cycle effect, allowing more work to be extracted from a given compressed charge. Another interesting feature of this design is the use of storing compressed air in a tank, denoted by ' $D$ ' in Figure 7 . The stored air was used to start the engine. The concept of storing compressed air has been revisited in more recent split-cycle designs to greater effect, given the advances in control systems, these will be discussed later. 


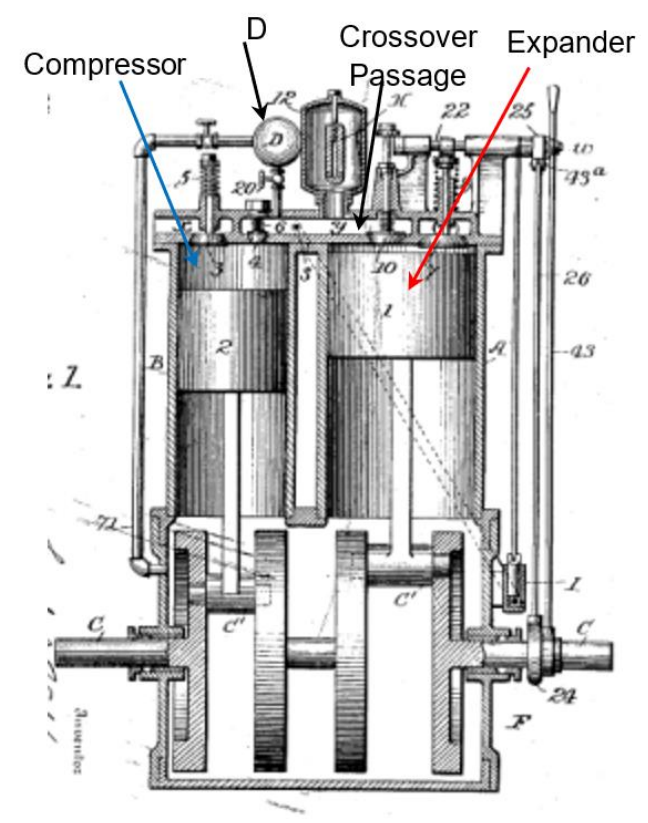

Figure 7 Webb's engine, 1913 [9] (annotations added)

The design by Black in 1957 [3] is the earliest found use of the term 'split-cycle engine'. This design differs from many that will be discussed in that it has a V-type arrangement and uses a rotary sleeve valve. These differences are not fundamental to the cycle itself but may offer some advantages in terms of packaging and airflow. The most crucial difference is that the compressor is external to the engine, so both the cylinders shown in Figure 8 are expansion cylinders. It was suggested that the compressor can be driven separately and therefore at a different speed to the expansion pistons. The compressor speed can be adjusted to maintain a pressure vessel (not shown) at constant pressure. This pressure vessel then supplies charge to the engine.

It is pointed out by Black that thermal efficiency is a function of the expansion ratio, and the split-cycle design allows setting a high expansion ratio independent of the compressor. Additionally, the split-cycle arrangement enables an optimally designed compressor without the concern of autoignition, as in conventional premixed charge spark ignition engines, since there is no fuel present at the compression stage. High thermal efficiency is promoted as the main advantage of this design. Other advantages include enabling a small piston clearance volume, such that less residual gas remains in the cylinder, allowing more inducted gas and potentially greater volumetric efficiency.

The notion of using one compressor at a higher speed to deliver air to multiple expansion cylinders also seems advantageous for packaging and weight. Also, if each 
power stroke gives similar power to that of a four-stroke cylinder, this would result in a more power dense engine since there is one power stroke every crankshaft revolution.

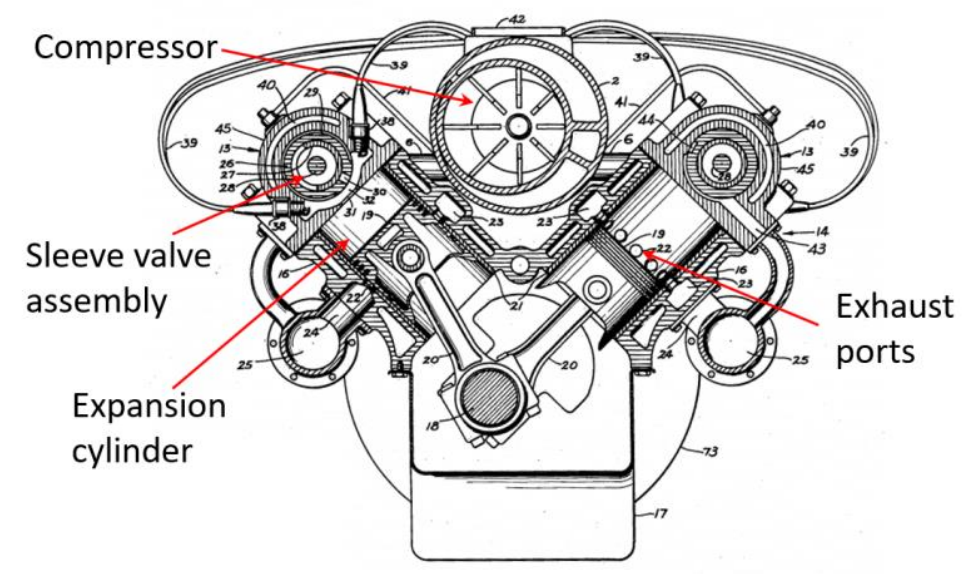

Figure 8 Black's engine, 1957 [3] (annotations added)

A series of patents applied for by General Motors Corporation, 1974-1975 [10, 11, 12] describe more split-cycle engine designs. The latest of these integrates the crossover passage with the expansion cylinder, where previously the crossover passage was completely separated from the two cylinders with valves [10]. The transfer port would therefore contain a large amount of residual combustion gas at the end of the exhaust process. The charge from the compression cylinder would be mixed with this residual gas forming up to $50 \%$ of the mixture. The main claimed benefit of this design is to reduce the formation and therefore emissions of Nitrogen Oxides ( $\left.\mathrm{NO}_{\mathrm{x}}\right)$. However, this effect can also be achieved by using, for example, exhaust gas recirculation (EGR). In the design description, it was acknowledged that the transfer passage and the additional valve will reduce volumetric efficiency compared to a conventional engine. There are no claims for higher power or efficiency, the focus was primarily for lower $N O_{x}$ emissions. It can be seen that the rationale behind this engine is different to that of Black's design, in that Black aimed to exhaust as much of the combustion products as possible to increase volumetric efficiency and had not considered emissions specifically. 


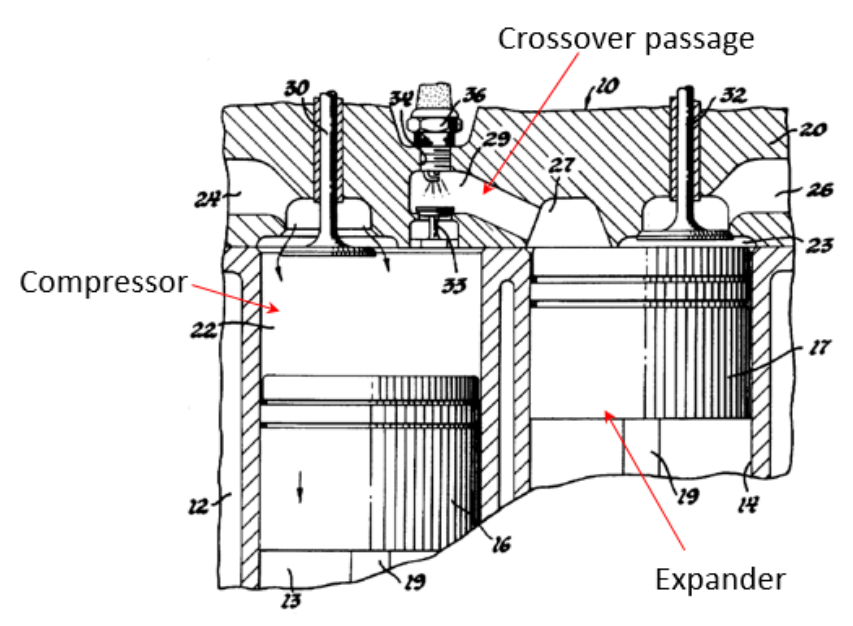

Figure 9 General Motors, 1975 [10] (annotations added)

In Ruiz's study on regenerative engines [4], further summaries of designs can be found. While the focus of the study was regenerative engines, many of the engines which are discussed may be classified as split-cycle engines. One engine of interest in the study is Stang's engine [13]. While this design does not strictly adhere to the split-cycle definition, it is of interest because it is one of the few designs that has been built and it shares many features of a split-cycle engine. Combustion takes place in the expander as the compressed charge is passed from the regenerator into the expansion cylinder with all valves closed. It was proposed that on the upward stroke of the expansion cylinder, as the combustion products are passed through the regenerator, the exhaust valve would open and $10-20 \%$ of the working fluid would be exhausted. In the same stroke, this would be followed by the intake valve opening, where this $10-20 \%$ of the fluid is replaced by fresh air. Ruiz states that the engine had disappointing results, 'The main problem was pushing the fuel and air mixture into the expansion cylinder during the time allotted to it [4]. This suggests there may be air flow issues and low volumetric efficiencies associated with this type of engine. 


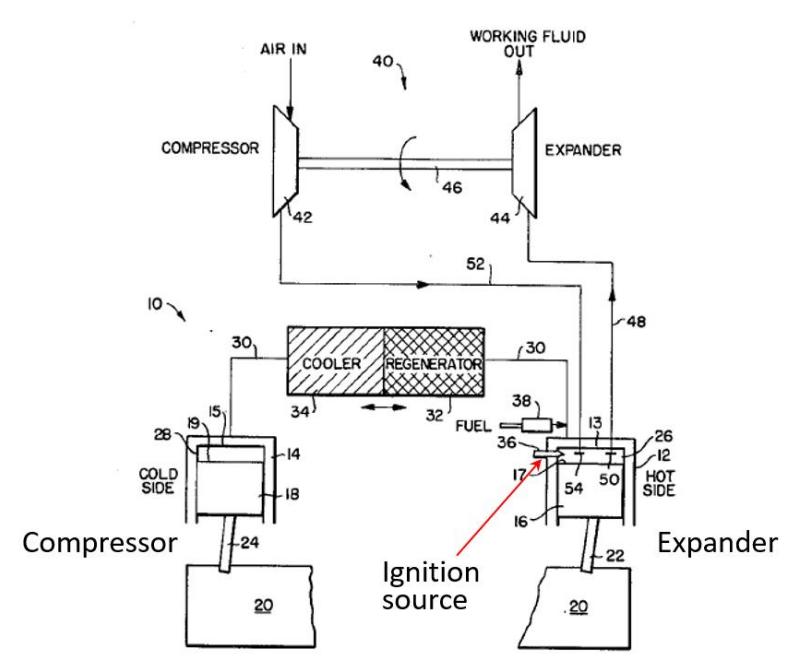

Figure 10 Stang's engine, 1982 [13] (annotations added)

\section{Existing Split-cycle Engines}

There are few existing examples of split-cycle engine prototypes. Given that the concept has been around for over 100 years, the few functioning examples is surprising and suggests that there may be significant practical challenges with these engines. However, the requirements of engines have significantly changed since many early split-cycle designs. Fuel consumption, directly linked to $\mathrm{CO}_{2}$ emissions, and minimisation of harmful $\mathrm{NO}_{x}, \mathrm{PM}$, and $\mathrm{HC}$ emissions are now primary considerations for engine design because of environmental concerns and regulations. This was not the case historically which could explain the absence of split-cycle engines in the past as the practical challenges outweighed the potential benefits of improved fuel economy and/or reduced emissions. With increasing environmental pressures, the potential benefits of split-cycle operation are more appealing to engine designers. The split-cycle concept has been revisited in recent years possibly because the benefits/drawbacks trade-off has shifted to a point where the concept warrants thorough investigation.

The split-cycle engines which do exist, or have recently existed, will now be discussed. Test data is presented where available. Also, the various claims for the benefits and drawback to the split-cycle are also presented. 


\section{Ruiz's Engine}

Following a thermodynamic study by Ruiz, which will be discussed later, a test engine was built and findings presented [14]. A schematic of the engine configuration is given in Figure 11. Notably, there was a porous ceramic matrix inside the combustion cylinder. This was used to recover exhaust heat. As exhaust gas leaves the combustion cylinder it passes through and loses heat to the regenerator, which is then picked up by incoming air-fuel mixture from the transfer pipe.

The main finding of Ruiz's tests was ultimately that the engine did not produce any useful work. Once the regenerator heated up, the air-fuel mixture would ignite before the regenerator. This meant that the regenerator worked in the reverse direction to that which was intended, resulting in the engine producing zero, or negative work. Other concerns with the design included the need to run at very low speeds (typically below $600 \mathrm{rpm}$ ) to allow time for regeneration. Very lean (40:1 air/fuel ratio) mixtures were required to limit the surface temperature of the regenerator to $1100^{\circ} \mathrm{C}$. Perhaps more interestingly, Ruiz states that the engine could produce only a small amount of positive shaft work when the regenerator was removed. This suggests that not all of the problems encountered were caused by the regenerator. It was also found that the peak cylinder pressure in the compression cylinder was only 2 bar absolute. This was attributed to a large 'dead volume' in the cylinder head and in the transfer pipe. It was retrospectively suggested that using an external dedicated compressor would be a better option.

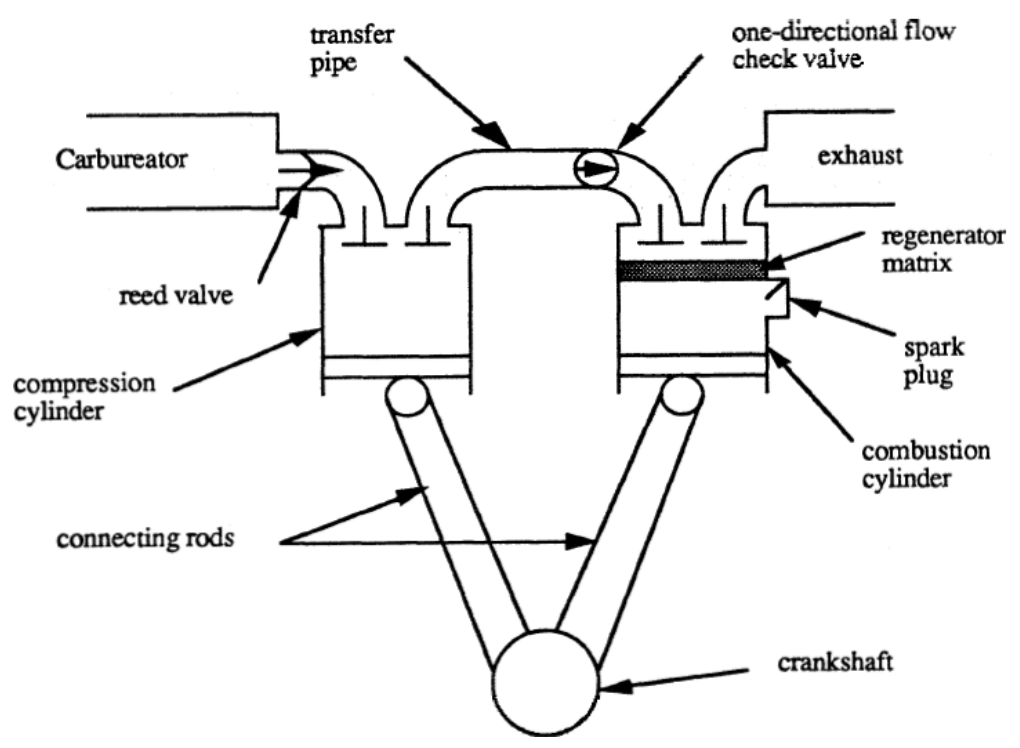

Figure 11 Ruiz's engine, 1993 [14] 


\section{Scuderi Split-cycle Engine}

Scuderi Group Ltd has registered over 200 patents relating to split-cycle engines up to the time of writing, the first being in 2003 [15]. The Scuderi engine first fired in 2009 and the engine is shown schematically in Figure 12. Scuderi group outlined some of the design features and findings from the engine design and testing in a series of papers from 2011-2012 [5, 16, 17, 18].

The design, as described in the first paper [5], can be seen as the split-cycle in its most basic form, and is not too distant from Webb's 1913 design [9]. This is because it uses none of the unique split-cycle benefits listed earlier by Dong [7]. A small volume ratio, expansion cylinder to compression cylinder, of 0.88 was used. The ratio is the opposite of what would be expected for a Miller cycle operation, instead using a larger compressor cylinder for 'cylinder supercharging'.

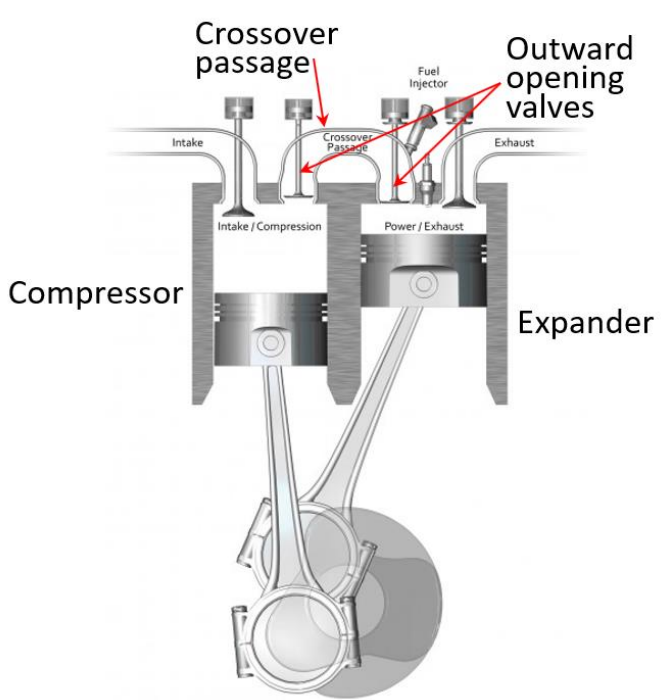

Figure 12 Schematic of Scuderi engine arrangement [19] (annotations added)

Following building and testing of the engine, the claimed benefits of the Scuderi engine can be summarised as follows:

1. Increased flexibility in optimising processes;

2. Ability for Miller cycle type operation, or cylinder supercharging, by using different cylinder volumes;

3. Increased charge motion leading to enhanced, faster combustion;

4. Reduced likelihood of autoignition;

5. Ability for pneumatic (air) hybridisation;

6. Reduced $\mathrm{NO}_{x}$ emissions, compared to conventional engines using EGR. 
While elsewhere it is claimed there is better fuel efficiency than Otto-cycle engines [20], this is omitted from the technical papers published by the Scuderi Group, and no definitive value for the efficiency of the engine is given. However, it is said a brake thermal efficiency is expected to be less than the $32 \%$ value predicted [5], which does not exceed the efficiency of conventional engines. In short, the published test data does not show a thermal efficiency advantage over conventional engines.

Test results can be seen in Figure 13, comparing simulated to measured brake mean effective pressure (BMEP) data. The test data fell short of the simulation predictions. Taking the highest measured BMEP value for each operating speed, a reducing trend in BMEP can be seen as the speed increases. This suggests that air flow through the engine is restricted, most likely due to the crossover passage and restrictive crossover valves. Also, it can be seen that the BMEP values are relatively low compared to conventional naturally aspirated engines, which are typically 8.5-10.5 bar [21].

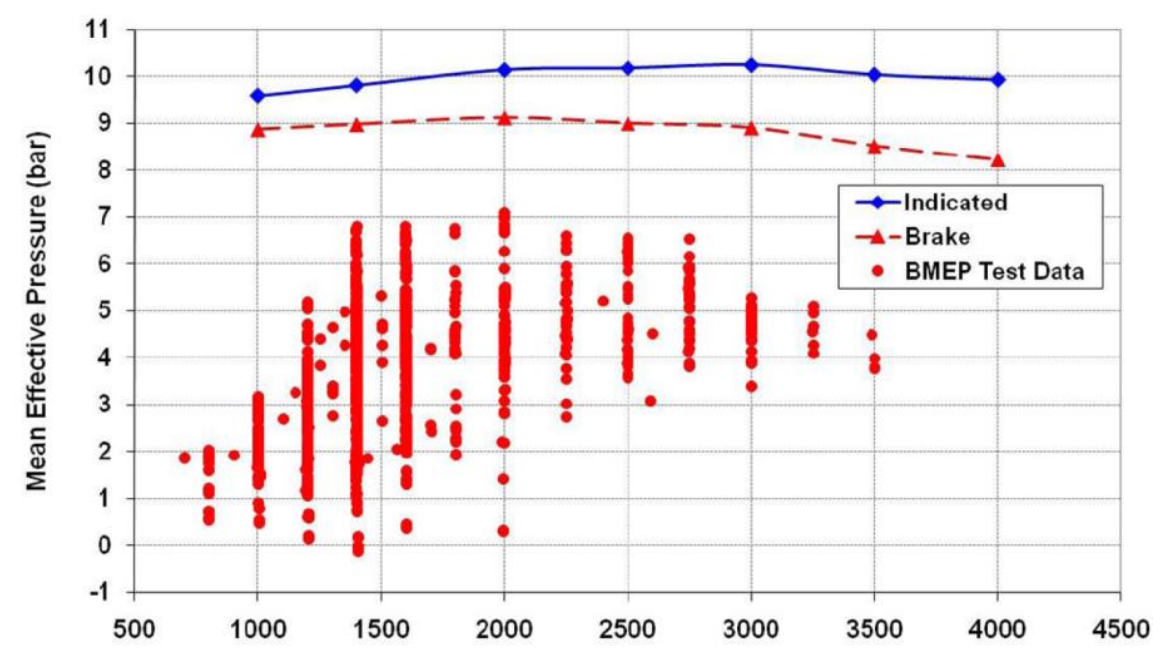

Figure 13 Simulation predictions and test data of IMEP and BMEP vs. Engine Speed, Scuderi engine, 2011 [5]

The results from the Scuderi group's testing highlights a trade-off in the expansion cylinder design. 'For efficiency reasons, it is clearly preferable to achieve combustion as close as possible to TDC, however in the [Scuderi] engine this has to be traded off against the need for adequate [crossover] valve opening duration' [5]. The expander side crossover valve closes around $25^{\circ}$ ATDC. This leads to a need to have combustion initiated while the expander side crossover valve is still open, and combustion after TDC. The effect of late combustion can be seen in Figure 14. The second pressure peak was achieved approximately $35-40^{\circ}$ after TDC. 


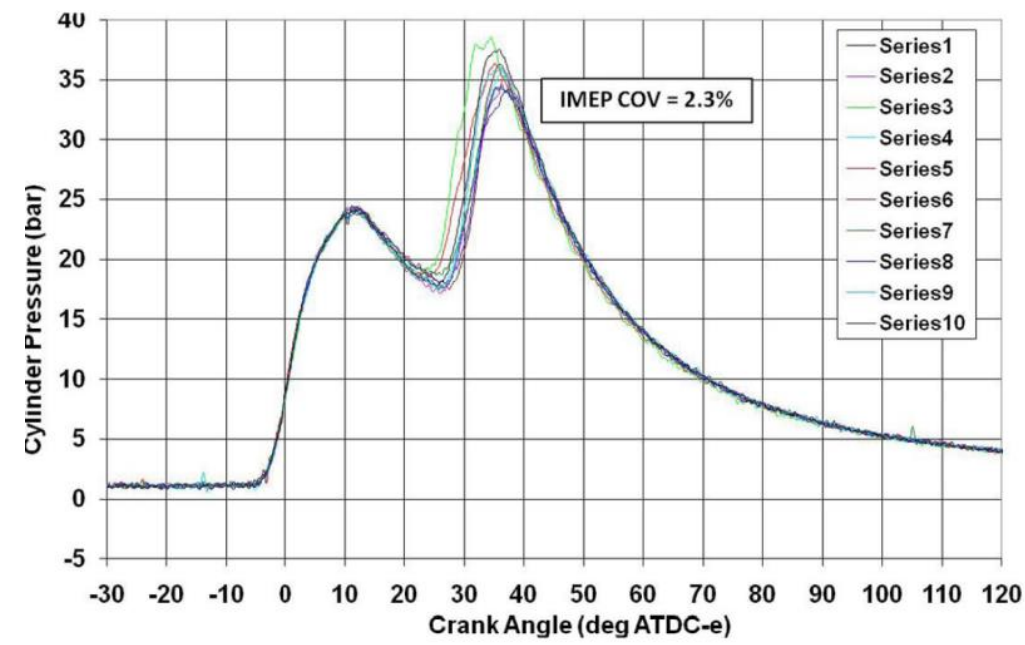

Figure 14 Measured Scuderi engine expander cylinder pressure at 3000 rpm 60\% full load, 2011 [5]

Considering how in the split-cycle expander charge is inducted and ignited in the same downward stroke, its operation is similar to that of the Lenoir IC engine. The Lenoir engine, made in 1860, was the first commercially successful IC engine [1]. It operated as a two-stroke SI engine in which as the piston descended from TDC a mixture of air and gas was inducted. The intake valve closed some time before halfway through the stroke. The mixture was then ignited raising the cylinder pressure and expansion took place in the second half of the stroke. The combustion products were exhausted as the piston returned to TDC. The late combustion meant expansion was very incomplete which was one reason, among many, for the low thermal efficiency (around $4 \%$ ) [1]. However, the key difference in the case of the split-cycle is of course that the inducted charge is pre-compressed and pre-heated, not atmospheric. While the expander induction event in the Scuderi engine is much shorter than the Lenoir engine, the fundamental induction/combustion trade-off remains.

In the Scuderi engine, combustion after TDC is credited for the low $\mathrm{NO}_{\mathrm{x}}$ emissions, as there are lower peak cylinder temperatures.

Other reported difficulties and issues found with the Scuderi engine included:

1. Losses across crossover valves;

2. Energy losses due to heat conduction through crossover port walls;

3. Thermal management and thermal loading due to having one cold cylinder, and one hot cylinder;

4. High carbon monoxide emissions, 2-3 times conventional engines, suggestive of poor air-fuel mixing. 
The timing of the crossover valves is also of concern with a split-cycle engine. Valve events used by Scuderi are shown in Figure 15. There is little time available for the crossover valve events. Each crossover valve is only open for $30-40^{\circ}$ crank angle, resulting in valve accelerations similar to motorsport engines [16]. In addition, the valves have to be opened, and also remain closed, against large pressure differences between the port and the cylinder. In order to actuate the crossover valves mechanically for such a short duration a large diameter cam as shown in Figure 16 was required. Since the crossover valves open very close to TDC and the cylinders have a high geometric compression ratio, the valves must open outward and away from the piston, unlike conventional engines that open towards the piston.

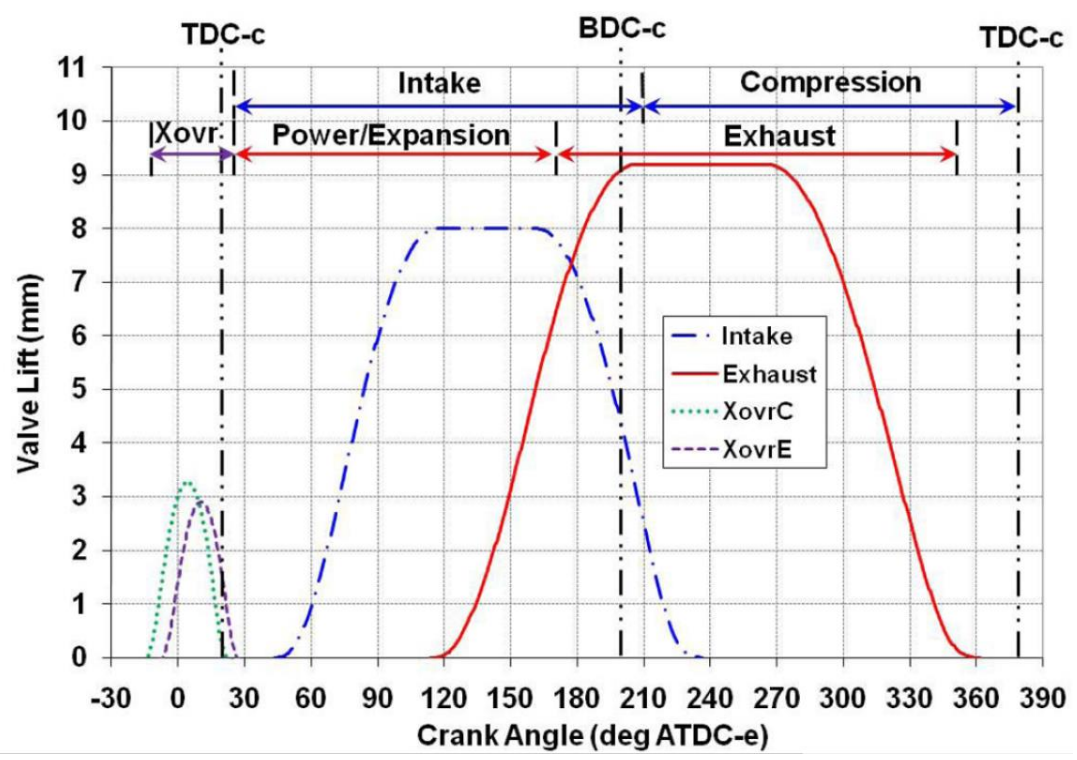

Figure 15 Scuderi engine valve lift profiles, 2011 [5]

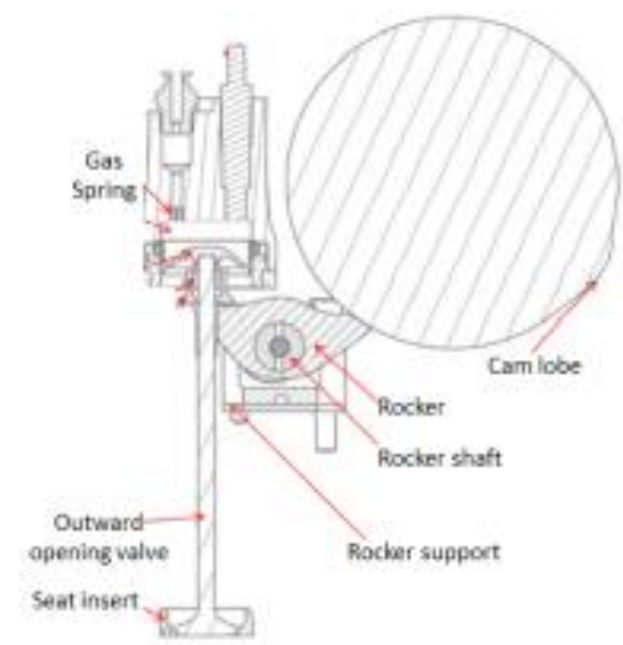

Figure 16 Scuderi crossover valve actuation assembly, 2011 [16] (annotations added) 
The concept of air hybridisation opens up more possibilities for a split-cycle engine [18]. This concept makes use of an additional tank which can store excess compressed air, shown in Figure 17. Regenerative braking of a vehicle can potentially be achieved by disabling the expansion cylinder (achieved by keeping the expander crossover valve closed) and the recuperated braking power used to drive the compressor to deliver air to the storage tank. The stored compressed air can then be used to drive the expander cylinder when required.

This method would require at least two stage variable valve actuation (VVA) for the crossover valves, which already have a number of difficulties associated with them, as mentioned earlier. Mild electric hybridisation can be used as an alternative. The use of Integrated Starter-Generators (ISG) is already a proven method [22]. Mild electric hybridisation has potential to store larger amounts of energy with batteries, compared to air hybrid concepts. Batteries are more energy dense than a practical compressed air tank. However, an air hybrid is more suited to frequent and fast charge-discharge cycles, as its storage capacity will not decay over time like a battery.

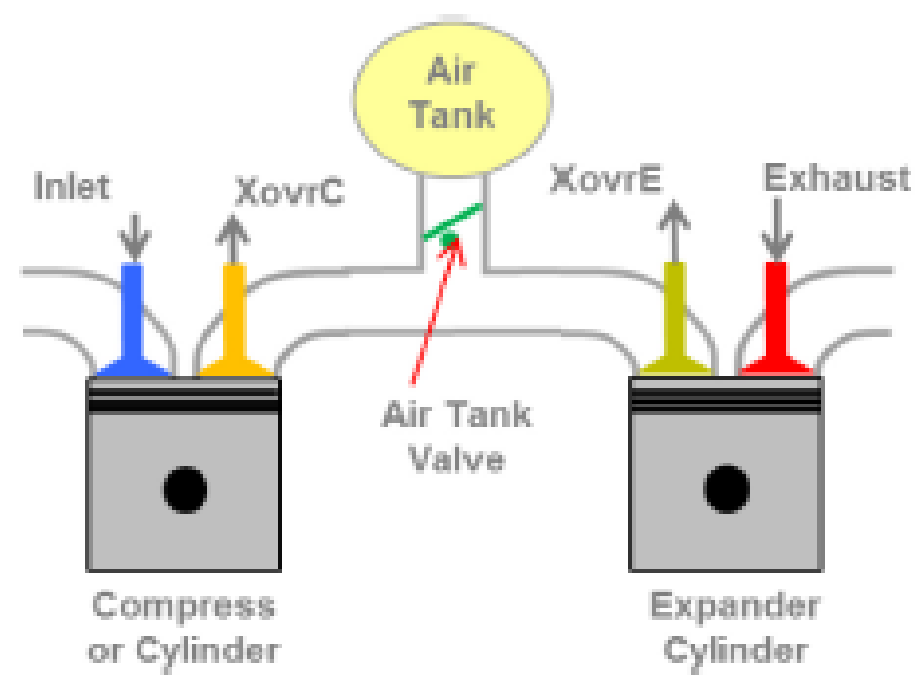

Figure 17 Scuderi air hybrid arrangement, 2012 [18]

In a simulation study the Scuderi group found that the use of a turbocharged split-cycle configuration with a downsized compression cylinder, enabling Miller-cycle operation, would give fuel consumption levels comparable with the best production gasoline engines, with best values of brake specific fuel consumption $240 \mathrm{~g} / \mathrm{kWh}$ given [18]. The air hybridisation would give additional efficiency benefits, depending on the mode of operation. This is yet to be proven in practice. 


\section{Stationary Power Generation 'IsoEngine’}

The IsoEngine was a large capacity (175 litre), compression ignition engine developed by RWE npower, beginning in 1992. A demonstrator was built and tested at Ricardo between 2001-2003 [23]. The rights to the engine were sold to Mitsui Engineering and Shipbuilding in 2003. After various issues, the IsoEngine was discontinued in late 2004 [24].

This engine aimed to take full advantage of the separation of cylinders by actively cooling the charge in the compression cylinder and including exhaust heat recovery. The IsoEngine is characterised by two main features, isothermal compression and isobaric combustion. Isothermal compression is achieved through injecting liquid water into the compression cylinder at a rate such that temperature is kept constant. Isobaric combustion arises from combustion taking place in an expanding cylinder [25].

Key claimed benefits include $[23,26]$ :

1. $60 \%$ electrical efficiency predicted, higher than conventional engines;

2. Lower $\mathrm{NO}_{x}$, and $\mathrm{CO}_{2}$ emissions compared to conventional large engines.

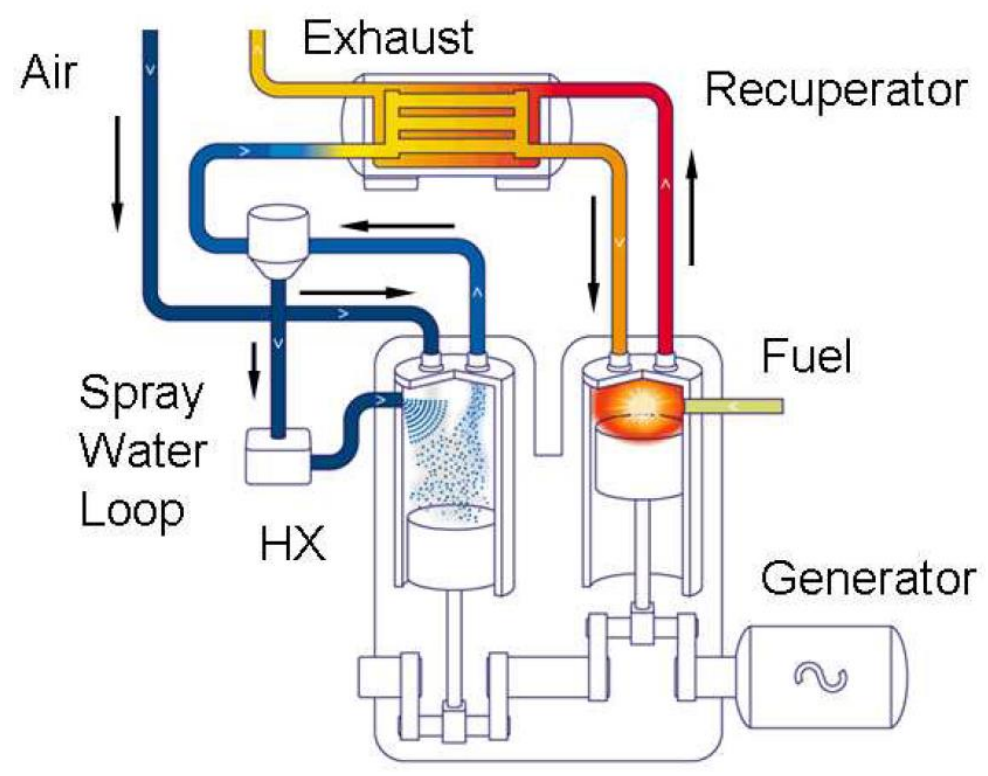

Figure 18 Simplified schematic of IsoEngine, 2004 [27]

As seen with the Scuderi engine, the IsoEngine also has combustion occurring while the crossover valve, or expander inlet valve, is open. The expansion cylinder inlet valve is open from TDC to $40^{\circ}$ ATDC, and combustion occurs from TDC to $50^{\circ}$ ATDC. However, this was not reported to be a problem. 
Near isothermal compression was demonstrated by testing at $410 \mathrm{rpm}$ [27]. However, the method of isothermal compression severely limits the operating speed of the engine, as time is needed for heat transfer from the air to the injected water. Most of the water is not evaporated because the temperatures remain low. The water is instead separated from the air downstream of the compressor to be cooled and reused. The mass of water injected is approximately three times the mass of the air that it is cooling [25].

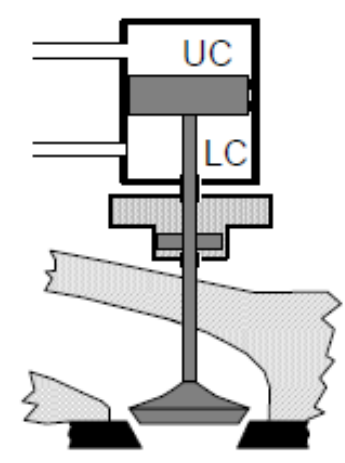

Figure 19 IsoEngine crossover valve concept [25]

While the Scuderi engine used a mechanical camshaft to operate the crossover valves, the IsoEngine uses 'bounce valves', shown in Figure 19. The valve is attached to a piston which is exposed to an upper pressure and lower pressure reservoir. The valve opens when this pressure difference is overcome by the pressure difference between the cylinder and the crossover port. This overcomes the challenges of a mechanical camshaft, but the crossover valves were found to be restrictive causing lower than expected volumetric efficiencies, of around $85 \%$, even at the low operating speeds. It was suggested that higher compression ratios should be used, than the value of 25:1 on the IsoEngine [24].

Realisation of the predicted $60 \%$ efficiency was not achieved for several reasons, mainly because of trade-offs with thermal management but also due to the restrictive crossover valves and poor combustion. It was concluded that the [demonstrator] did not reach a significant power output due to poor combustion' [27]. A significant amount of smoke was produced by the engine despite there being more than enough air available for combustion. This suggests poor air-fuel mixing, which was also found on the Scuderi group's engine, which produced high levels of carbon monoxide.

Thermal management of the expansion cylinder was a challenge. This is because the inlet air temperature to the expansion cylinder was around $700^{\circ} \mathrm{C}$, so there was no 
thermal relief from low temperature inlet air as occurs in a four-stroke engine. Combustion temperatures were limited by a combination of using a lean mixture $(\lambda=1.56)$, combustion after TDC and having large quantities of water vapour present in the charge air. However, there was still consistently high temperatures in the expansion cylinder. A Nimonic alloy was required for the piston crown. Also, an advanced austenitic steel alloy NF709 was needed for the heat exchanger to tolerate temperatures up to $750^{\circ} \mathrm{C}[28]$.

Example test results at $367 \mathrm{rpm}$ gave net indicated power of $266 \mathrm{~kW}$, and shaft power of $136 \mathrm{~kW}$, for a fuel mass flow rate of $17.7 \mathrm{~g} / \mathrm{s}$ [24]. This is calculated by the present authors to give 2.5 bar indicated mean effective pressure (IMEP) and, assuming the fuel to be regular diesel with a $42500 \mathrm{~kJ} / \mathrm{kg}$ lower heating value, gives an indicated fuel conversion efficiency of $35.4 \%$. IMEP is most appropriately defined below.

$$
I M E P=\frac{\text { net indicated cycle work per cycle }}{\text { total swept volume }(\text { compressors }+ \text { expanders })} \quad \text { Eq. } 1
$$

This implies a split-cycle engine of the same mean effective pressure as a conventional four-stroke engine will give more power as the cycle takes place over one crank revolution, rather than two as per conventional four-stroke engines. The IsoEngine was reported to be discontinued due to mechanical problems with many of the new components such as the 'bounce valves' and thermal loading caused by temperature gradients between cylinders. Sealing issues with the compressor cylinder also caused water leaks into the crankcase when the engine speed was increased to 600 rpm, imposing speed limitations. A more recent analytical study published in 2015 [7] gave the IsoEngine a slightly lower brake thermal efficiency prediction of $53 \%$.

\section{Tour Engine}

The Tour Engine [29, 30] is still undergoing development at the time of writing, with the most recent reported prototype being operational in 2012 [31]. A unique feature of this split-cycle engine is the opposed piston arrangement, depicted in Figure 20. The arrangement allows minimisation of the crossover passage size between the cylinders, reducing pressure losses and increasing efficiency of the charge transfer process. While the arrangement will affect each process, the cycle which the working fluid undergoes is fundamentally the same as the Scuderi engine. 


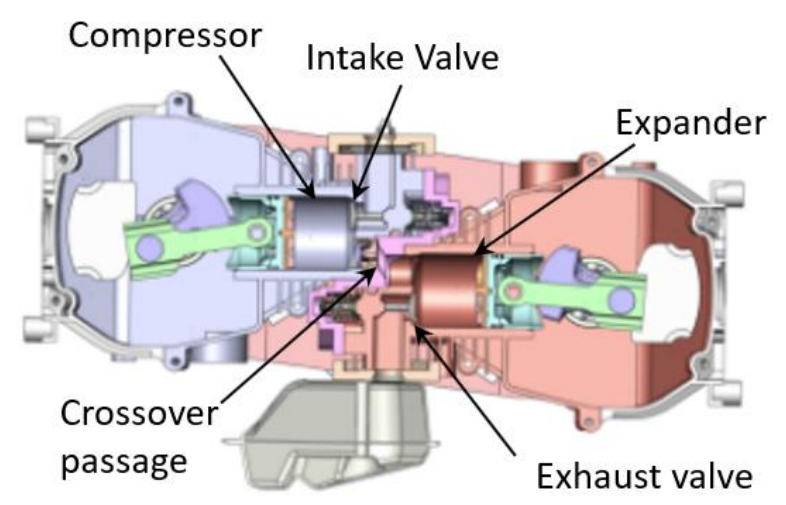

Figure 20 Tour Engine configuration [31] (annotations added)

The key claimed advantage of the Tour Engine is increased thermal efficiency, described as a 'quantum leap' compared to conventional four-stroke engines [31]. This is primarily attributed to the effect of using a larger expansion cylinder to give more complete expansion and therefore reduced exhaust losses, as per the Miller cycle. It is also claimed that less energy is lost to the cooling system because less cooling is needed, increasing efficiency. The claim is at odds with the previously discussed designs where thermal management presented significant challenges. It can be seen in Figure 20 that the engine is air-cooled. This could suggest the engine has a low power density omitting the need for a demanding cooling system as described for the IsoEngine. While it is claimed that the engine is more efficient, there appears to be no published results to substantiate this claim.

The second significant claimed advantage of the engine is a reduction in emissions. This includes $\mathrm{CO}_{2}, \mathrm{CO}, \mathrm{NO}_{x}$ and $\mathrm{HC}$. Again, there are no known published test results to support this.

One other notable feature of the engine can be concluded from the interesting compression cylinder pressure-volume trace in shown Figure 21, showing that the crossover valve must close before TDC. 


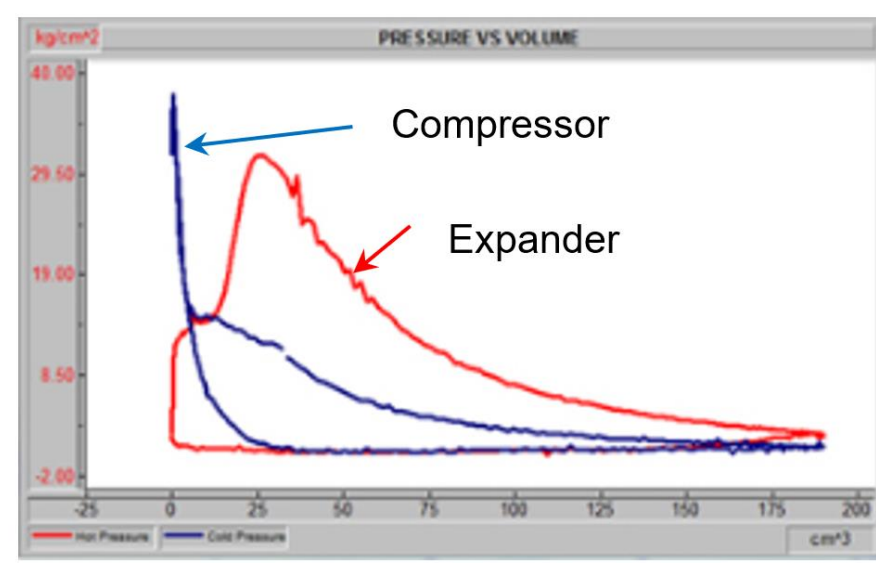

Figure 21 Pressure-Volume test data for Tour Engine prototype 2 [31] (annotations added)

\section{Modern Split-cycle Designs}

Over recent years, there has been a significant increase in the number of patents concerning split-cycles. At the very least this shows there is an increased commercial interest around split-cycle engines. This is probably due to the possibility of the splitcycle increasing IC engine efficiency which is of increasing importance to engine designers. Some of the more recent designs will now be discussed. These are recent designs for which entire engine prototypes are not known to exist, unlike the fully working Scuderi and Tour engines.

\section{Variable Engine Modes}

Caterpillar Inc. has several patents regarding Split-cycle engines. The earliest being from 1996 [32], which describes a split-cycle engine with an additional expansion cylinder placed after the combustion cylinder. The most recent split cycle designs, from 2014 [33, 34], describe added control methods to improve the cycle. The design has a series of cylinders that can either operate as a compressor or expander depending on the needs of the engine. Each cylinder is connected to the intake manifold, exhaust manifold and a transfer (cross-over) manifold, as shown in Figure 22. In compressor mode, the cylinder draws from the intake manifold and pumps into the transfer manifold. In the combustion mode, the cylinder intakes from the transfer manifold and discharges to the exhaust manifold. It is claimed this can solve a lot of the heat distribution and thermal loading issues usually present in split-cycle engines by alternating between compressor and combustor. A limitation of this design is that the compressor and expander cylinders are identical, therefore the compression ratio 
must equal expansion ratio. A similar design by Ford Global Technologies from 2002 is said to increase the power output by using compression cylinders to supercharge the engine [35].

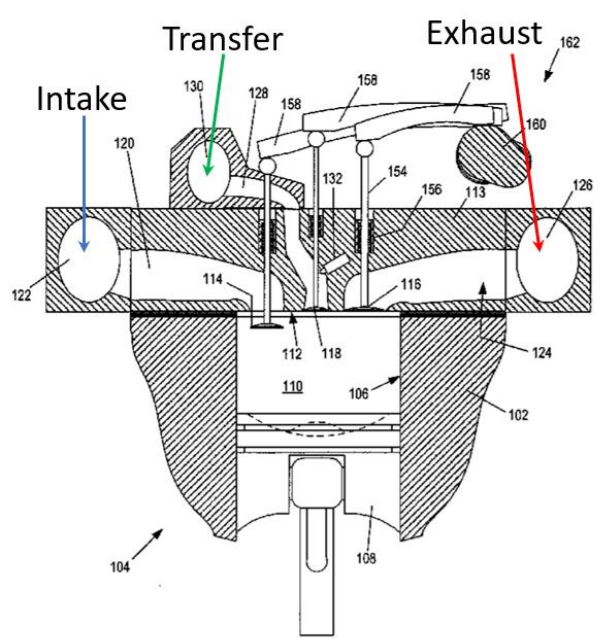

Figure 22 Caterpillar Inc, Fiveland's engine, 2014 [33] (annotations added)

\section{‘CryoPower’ Split-cycle Engine}

At the time of writing, the CryoPower engine is undergoing development by Ricardo plc and the University of Brighton [36]. The cycle and structure is very similar to that of the IsoEngine [22-27] in that heat recovery and isothermal compression are used. However, the CryoPower engine is designed for a different application to that of the IsoEngine. The CryoPower engine is targeted at heavy duty vehicles, such as long haul trucks, whereas the IsoEngine was designed for stationary power generation. This suggests that the IsoEngine showed potential despite its shortcomings.

To adapt the concept for automotive applications the isothermal compression is achieved through injecting liquid Nitrogen $\left(\mathrm{LN}_{2}\right)$ into the compression cylinder, instead of water. The $\mathrm{LN}_{2}$ could be produced on-board by a liquid nitrogen generator driven by the engine or carried in a dedicated tank like those used to store liquified natural gas (LNG) on many trucks [37]. Features that created issues on the IsoEngine, such as the crossover 'bounce valves', are again proposed on this engine. Other unique features to this design include a variable ratio transmission between the compressor and expansion cylinders meaning they can be driven at different speeds; thus enabling varying degrees of cylinder supercharging to be used [38].

Similar to the IsoEngine, it is predicted that the CryoPower engine will have $60 \%$ thermal efficiency [37], significantly exceeding current IC engine technology. Predicted 
high efficiency is achieved through cold compression, exhaust heat recovery and turbocharging.

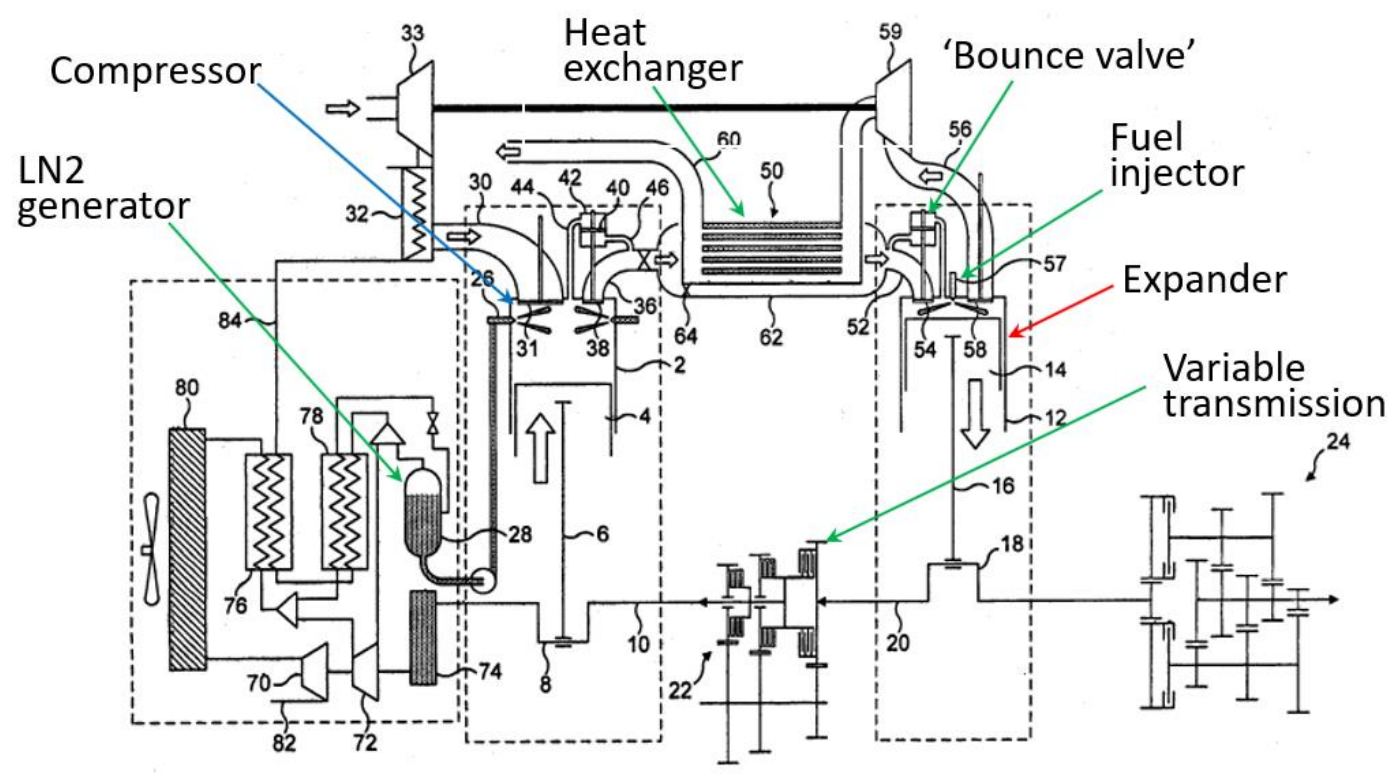

Figure 23 Ricardo ‘CryoPower’ engine schematic, 2014 [38] (annotations added)

As the most recent prototype found, a single cylinder, 1.125 litre, compression ignition combustor prototype was built and tested [37, 8]. The combustor is effectively the expansion cylinder of a split-cycle engine and is designed to work in the context of the CryoPower engine. Heated, compressed air is supplied to the cylinder by a separate subsystem to create the environment in which the combustor would operate. This allowed for a detailed investigation of split-cycle combustion, which was found to be a significant challenge on the IsoEngine. For this research engine some practical challenges that would normally be present are avoided, such as mechanical actuation of the crossover valves where an electro-hydraulic system was used.

Stable combustion was demonstrated at $800 \mathrm{rpm}$ and $1200 \mathrm{rpm}$ with typical diesel fuel, despite retarded combustion timing as required in a split-cycle engine. It was also found that the heat release rate was faster than in conventional diesel engines. A large pressure differences across the inlet valve gave a high velocity flow of inducted air leading to rapid mixing between the air and fuel. The high initial heat release was attributed to a high proportion of pre-mixed fuel and air.

Interestingly in this prototype, the process of air being inducted to the cylinder occurs in a short time before TDC and therefore the combustion timing can be advanced, with peak pressure being achieved approximately 5-20 ATDC as shown in Figure 24. In contrast, the Scuderi engine inducted air mostly after TDC, giving more retarded 
combustion timing, with peak pressure being achieved $30-40^{\circ}$ ATDC as shown in Figure 14. Although induction before TDC enables combustion phasing to be advanced, allowing more work to be extracted during expansion, it is achieved at the cost of additional compression work as the piston returns to TDC. This trade-off leads in favour of more retarded induction and combustion timing, in Figure 24 the pressure trace labelled as '13' (dashed lines) gave a torque of $94.3 \mathrm{Nm}$, compared to $58.8 \mathrm{Nm}$ for trace '06' (solid lines).

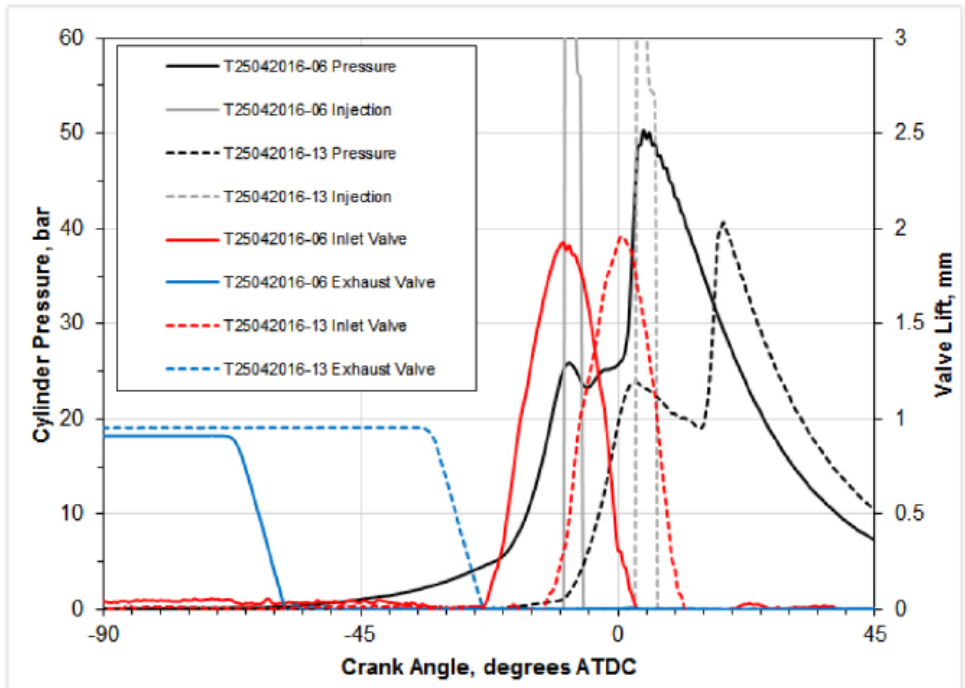

Figure 24 Experimental single cylinder combustor pressure trace at 800 rpm [8]

Similar to findings on the Scuderi engine, it was stated that 'the challenge is to induct hot high pressure charge air close to top dead centre into the combustion cylinder and then inject and burn the fuel before the piston has travelled significantly down the expansion stroke' [8]. While high velocity inlet flow is beneficial in terms of mixing and heat release rate, it is indicative of this deeper challenge associated with these engines. The large pressure differences across the inlet valve mean the flow is initially choked. In conventional engines, increasing engine speed will increase the pressure difference across the valve, and therefore increase the flow rates which partly offsets the reduced time for induction. In the split-cycle, the flow choke limit means increasing engine speed will not increase the initial flow rate through the valve. Additionally, as engine speed is increased less time is available for induction and combustion, and maintaining stable combustion in a rapidly expanding volume is a challenge. These factors suggest there will be engine speed limitations when trying to ensure there is enough time for induction. 
The test data provided shows evidence of significant engine speed limitations. Comparing results at $1200 \mathrm{rpm}$ to $800 \mathrm{rpm}$ for the most retarded combustion timing, which allows for most air to be inducted, air flow reduced by $40 \%$. The air flow rate reduced despite longer valve opening times in terms of crank angle and higher upstream pressure at the higher speed. Also, start of injection was much earlier at higher speed, $-7.5^{\circ}$ ATDC compared to $3^{\circ}$ ATDC, likely to allow time for combustion. This in turn advances the induction timing and will negatively affect fuel consumption as recompression of the fluid takes place before TDC. The apparent limitations to engine speed may result in a low power density engine.

The data obtained from this testing was used to provide empirical data to support simulations which calculate that brake efficiencies approaching 60\% are achievable, which exceeds current heavy duty diesel engines with thermal efficiencies around $45 \%$.

\section{Split-cycle with four-stroke combustion cylinder}

Some recent designs combine dedicated compression and expansion cylinders, as in a split-cycle, with cylinders operating on a four-stroke cycle. The following can be considered split-cycles in that compression and expansion take place in separate cylinders, with combustion taking place some time between. However, these engines fundamentally differ from those previously discussed because combustion takes place in a four-stroke cylinder as opposed to a two-stroke expander or in a crossover passage. These have been included in the review as they aim to address similar problems to the conventional split-cycle, such as independent optimisation of the compression and expansion processes. These engines may be considered as an intermediate between conventional four-stroke cycles and conventional split-cycles, and as such warrant a brief discussion.

The earliest known example of an engine of this type is that by Rudolf Diesel in 1887 [39]. Diesel's 'Series XIV Compound Engine' consisted of two four-stroke cylinders with an additional double acting cylinder which functioned as a compressor and expander. According to Cummins [39] the greatest issue with the engine was the extremely high heat loss which occurred during gas transfer from the high pressure four-stroke cylinder and the low pressure expander. This lead to double the fuel consumption of Diesel's Series XV engine which ran earlier than the compound engine 
and featured no second expansion stroke. As technology has advanced, the concept has been revisited. Some of these recent designs will now be discussed.

For example, Volvo Truck Corporation designs, 2015 [40, 41], demonstrate the combination of four-stroke and split-cycle features. The main intention of these engine configurations is to increase engine efficiency. This is achieved through having one or more stages of cold compression and fully expanding exhaust gases to atmospheric pressure through secondary expansion cylinders. In the engine design shown in Figure 25, three compression stages are used [40]. The primary compressors complete a first compression stage, and an intermediate compressor completes a second compression stage. The pre-compressed air is then transferred to the fourstroke cylinders where an additional compression stage takes place. Combustion takes place as in a conventional four-stroke cycle and the partially expanded gases are transferred to secondary expanders which extract more work from the combustion gases thus theoretically improving fuel efficiency.

A similar design from General Motors, 2013 [42], is depicted in Figure 26 and states the added benefit for reducing emissions. Similarly, a design from Honda Motor Co, 2017 [43], features separate compressor, power and expander cylinders with the aim of improving cycle efficiency.

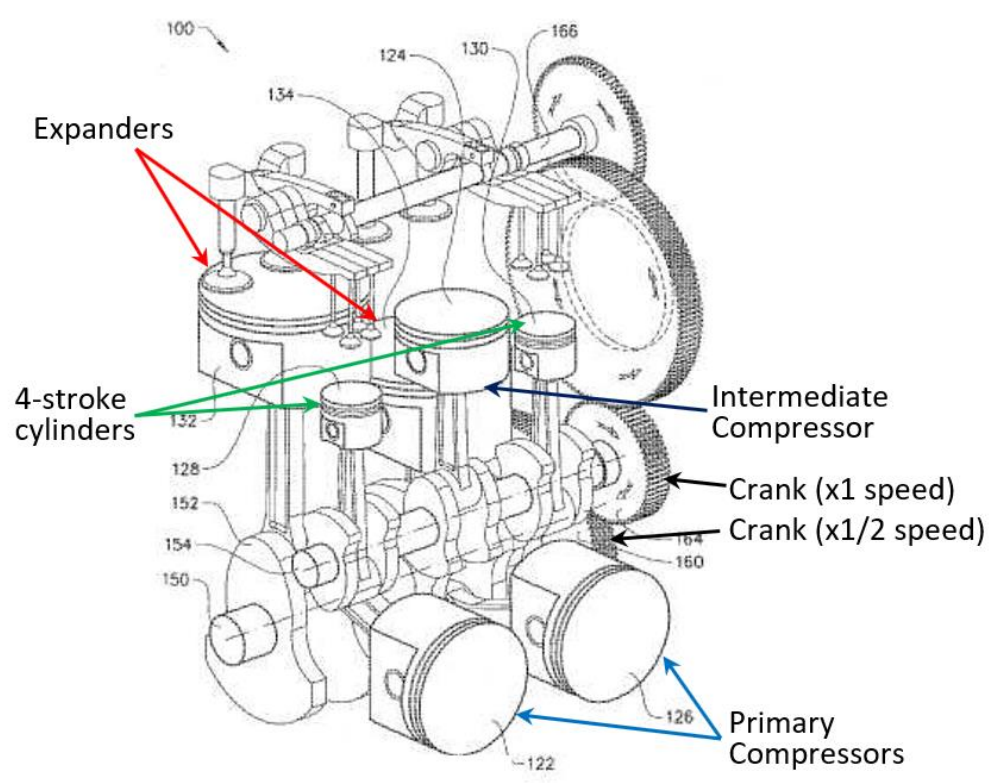

Figure 25 Volvo Truck, Andersson's engine [40] 


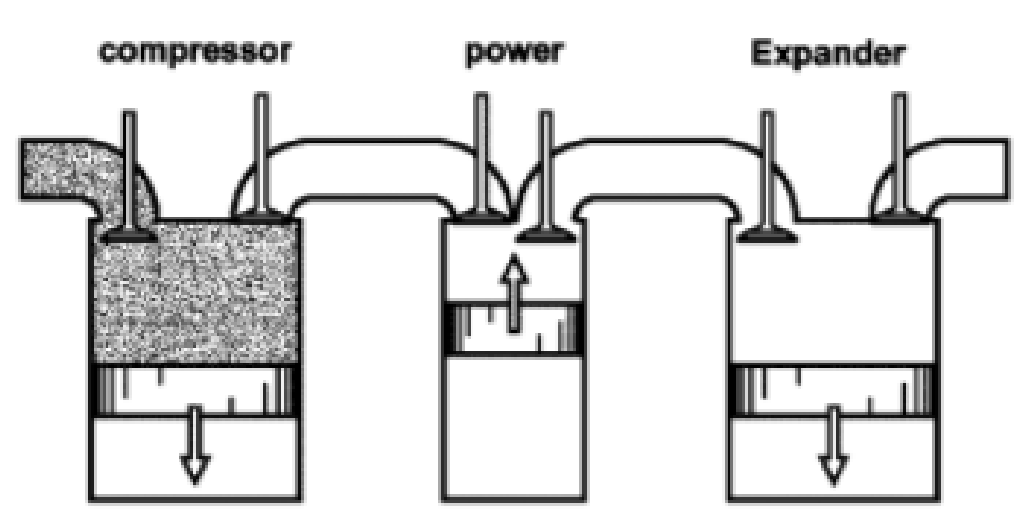

Figure 26 General Motors design, 2013 [42]

The five-stroke concept [44] consists of a conventional four-stroke cycle, followed by a further expansion in a low-pressure two-stroke expander. While this is a more significant departure from the split-cycle concept as there is no two-stroke compressor, the five-stroke has potential advantages of a second expansion stroke through increasing the effective expansion ratio. The IImor five-stroke engine [45] is a practical example of this concept and consists of two four-stroke cylinders which transfer the partially expanded combustion products to a secondary expander. The five-stroke prototype has demonstrated a $226 \mathrm{~g} / \mathrm{kWh}$ which is equivalent to a $36.1 \%$ fuel efficiency, with pre-catalyst emissions in line with typical SI engines. Durrett [46] assessed the potential benefits of a second expansion stroke, as in the five-stroke concept, compared with conventional four-stroke engines of the same rated power. Experiments showed a $1.1 \mathrm{~L}$ engine with a second expansion stroke gave an approximately $8 \%$ reduction in fuel consumption at medium/high load compared with a $1.4 \mathrm{~L}$ conventional turbocharged engine. Interestingly, modelling revealed that high pumping losses occurred at high load in the extended expansion concept due to the transfer stroke. The pumping work at the selected high load data point was approximately $8 \%$ of the brake shaft work, compared to just over $1 \%$ for the conventional turbocharged case. However, the energy recovered in the second expansion stroke more than compensated for these pumping losses to give a net efficiency improvement.

These engines differ from previously discussed split-cycle engines in that the combustion cylinder operates a four-stroke cycle. This avoids the previously stated challenge of inducting charge and having combustion close to TDC. Intercooling between compression stages offers a chance to reduce compression work. While this 
will be to a lesser extent compared to near isothermal compression as on the CryoPower engine, isothermal compression is applicable to these engines in the twostroke compression cylinders. Exhaust heat recovery between the cylinders is less desirable in this configuration, and intercooling is preferred instead as there is a compression stroke in the power cylinder.

A double compression expansion engine (DCEE), depicted in Figure 27, was analysed to assess the potential benefits of a cycle of this type [48] [49]. Although there are only two cylinders in this design, the low pressure (LP) cylinder doubles as a compressor and secondary expander. Simulations gave an indicated thermal efficiency of $60 \%$ and a brake thermal efficiency of $56 \%$ [48]. The motivation of this design is to simultaneously have low friction and have high peak cylinder pressures which give good indicated efficiency. Higher cylinder pressures require stiffer piston rings and larger bearings which increase frictional losses. In conventional engines, when increasing peak cylinder pressures, the larger bearings and other components which cause increased frictional losses are only necessary for a small fraction of the cycle. Additionally, as leaner air-fuel mixtures are used which can improve indicated thermal efficiency, friction becomes a higher percentage of the cycle net work.

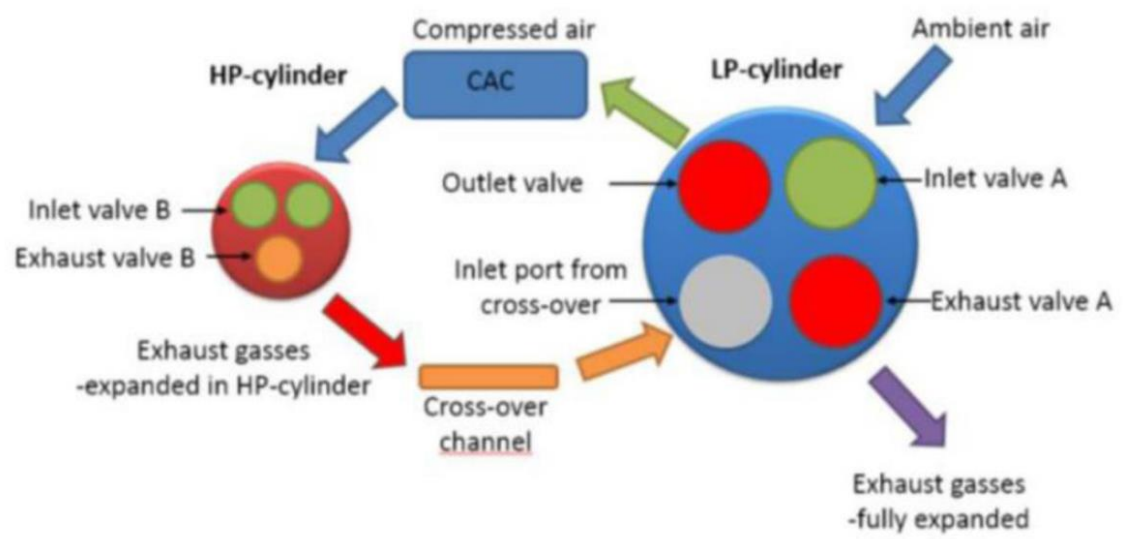

Figure 27 Schematic of Double Compression Expansion Engine (DCEE) concept [48]

By splitting the cycle in the DCEE it is suggested that efficiency is improved for the following reasons (the relative magnitudes of these effects are shown in Figure 28):

1. Net frictional losses become smaller as the larger LP cylinder can have smaller bearings/ lower tangential load piston rings;

2. Heat losses during combustion are reduced due to a small high pressure (HP) cylinder and thus a smaller surface area; 
3. Two stage expansion allows for a much larger effective expansion ratio leading to more shaft work from a given amount of fuel and therefore reduced exhaust losses.

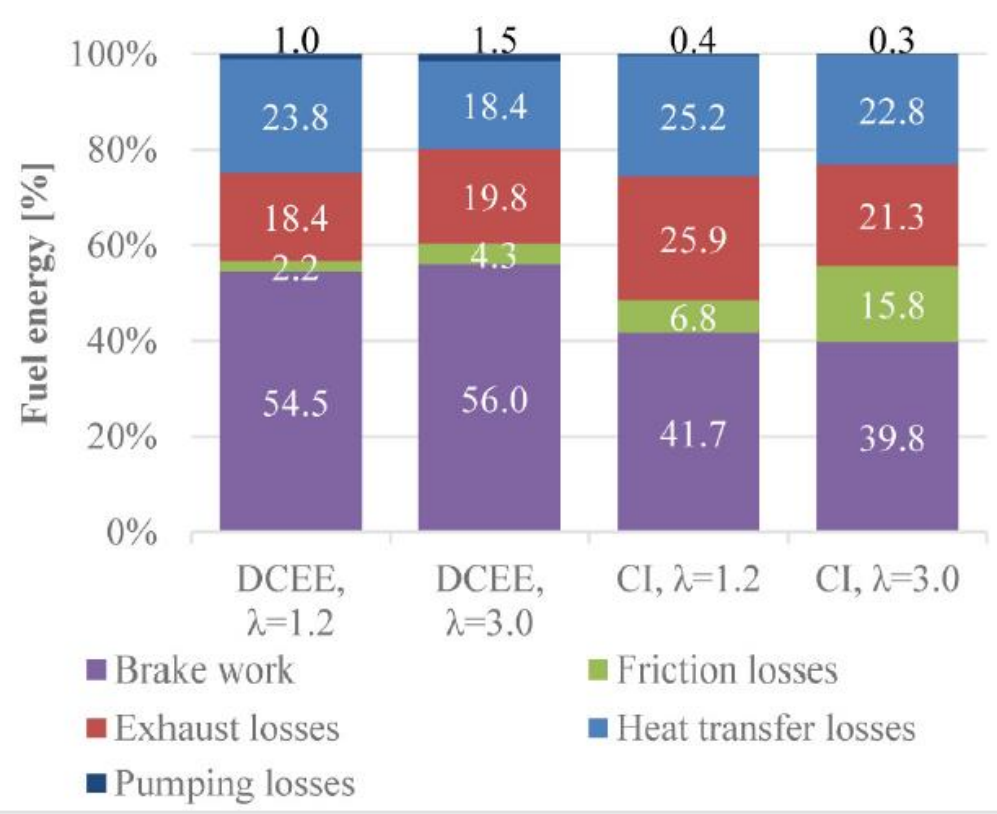

Figure 28 Energy balance of DCEE concept compared to $\mathrm{Cl}$ engine with equivalent compression ratio [48]

It was reported that the friction model used was simplistic, but by conservative estimates brake thermal efficiency should be in excess of $50 \%$ [48]. Also, it was found that the heat release profile had minimal effect on the brake thermal efficiency [49]. The findings of this study are yet to be proven in practice and exhaust emissions have not yet been considered. It is worth noting that a significant number of split-cycle practical challenges discussed are not present in this concept including; rapid actuation of crossover valves against large pressure differences; induction of sufficient charge into the expander at high engine speeds; thermal management of the expander due to no thermal relief of low temperature air; and initiating and maintaining stable combustion in a rapidly expanding volume.

\section{Additional Thermodynamic Analysis and Simulation Studies of Split-Cycle Engines}

Some studies and simulations have previously been discussed in context with their associated engine. This section includes information from other studies and extra information omitted from the previous discussion. It is apparent that there is a general lack of published information regarding the fundamental analysis of the split-cycle 
itself. The analysis would be very useful in order to validate the claimed benefits of split-cycle engines.

\section{Regenerative Split-Cycle}

Over the period from 1989-1991, Ruiz reported the earliest significant study relating to split-cycles $[4,47,50]$. The focus of the study was in fact relating to regenerative cycles, but crosses over significantly with what are now called split-cycles.

In an ideal thermodynamic analysis, the regenerative cycle has the possibility to almost double the thermal efficiency compared to conventional engines [47]. A computer model based study investigated the significance of various parameters relating to the configuration shown in Figure 29. It was concluded that an indicated thermal efficiency of $>40 \%$ could be achieved with a regenerative cycle of this type [4]. Significant parameters that effect performance include the phase angle between the cylinders, where an optimum value of $45^{\circ}-60^{\circ}$ is given. This value is the crank angle degrees the expansion cylinder leads the compression cylinder. It was also found that using a larger expansion cylinder than compression cylinder made little effect on thermal efficiency, but significantly reduced mean effective pressure, therefore power. Overall, relatively low IMEP values are predicted, in the region of 3-4 bar. It was also found that a smaller crossover passage volume is beneficial. As the crossover passage volume increased, the passage approaches acting as a constant pressure plenum.

There are concerns with some of the outcomes from this study. Firstly, the crossover valve timing, which inlets gas to the expander, was briefly investigated. It was found that closing the crossover valve at varying times after TDC made relatively little difference to performance. The crossover valve was allowed to close at $180^{\circ}$ after TDC, i.e. the valve is open for the whole combustion and expansion stroke. This is not realistic because very low performance would be expected due to back flow of the combustion gases out of the chamber.

Also of concern are the peak cylinder temperatures calculated. The study reports a value of around $6500 \mathrm{~K}$ for stoichiometric conditions, and a very lean theoretical mixture of $\lambda=2.5$ was required to limit temperatures to $2500 \mathrm{~K}$. Although heat recovery is used, $6500 \mathrm{~K}$ is still a very high temperature. It could be that this arises from the use of a constant specific heat capacity modelling assumption. This study resulted in this 
type of engine being made and tested which has been discussed previously [14]. The engine was reported to be unsuccessful and struggled to produce useful work.

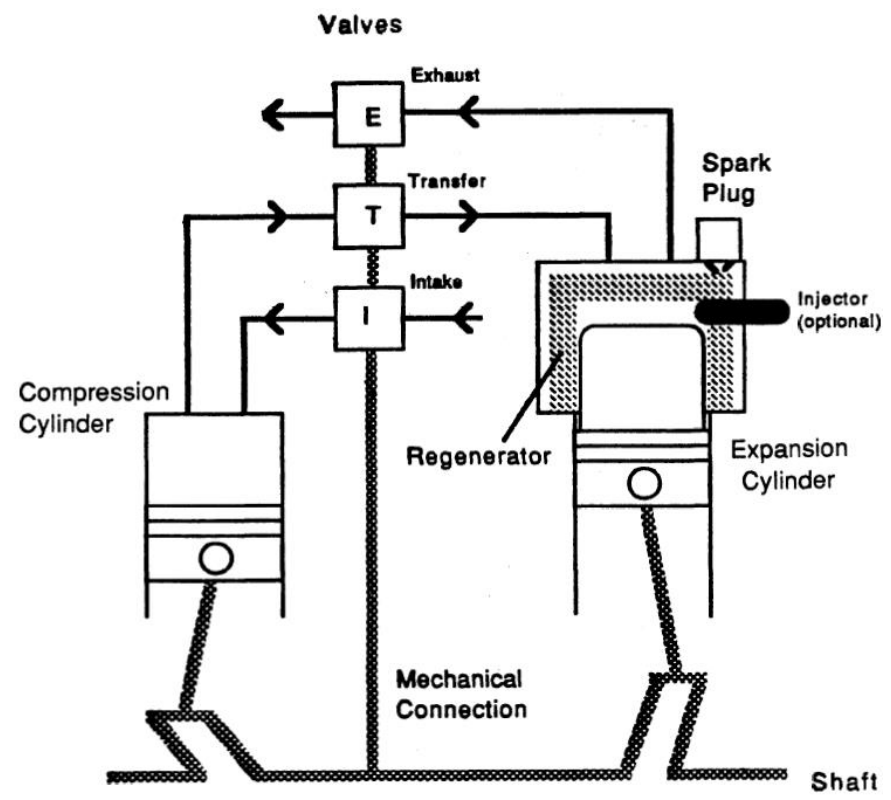

Figure 29 Ruiz's study, model configuration, 1991 [4]

\section{Diesel Engine Emission Reduction}

A number of studies have investigated split-cycle engines of a simpler configuration, using one crossover valve, no exhaust heat exchanger, and having a cylinder volume ratio of 1.2 (expander/ compressor). The crossover passage is incorporated into the expander. This engine configuration, shown in Figure 30, has been extensively investigated using computational fluid dynamics (CFD) modelling by the University of Pisa [51, 52]. The concept, named Split-Cycle Clean Combustion (SCCC), has also been investigated by Caterpillar and the University of Illinois using a one-dimensional model $[53,54]$. The configuration is similar to that of the 1975 General Motors design [10], the aim of which was to reduce emissions.

It was found the concept gives high indicated thermal efficiencies of approximately $46 \%$ [51]. The concept also promises to significantly reduce emissions giving both soot and $\mathrm{NO}_{x}$ reductions. It is stated that using this method will allow compliance with Euro 6 regulations without the need for expensive exhaust after treatment systems [52]. The reduced emissions are attributed to Homogeneous Charge Progressive Combustion (HCPC) by injecting fuel into the small crossover port.

The calculated indicated power values were in the region of $15 \mathrm{~kW}$, for a 1.1 litre naturally aspirated version of the engine operating at $2000 \mathrm{rpm}$, which corresponds to 
an IMEP of 4 bar. Other interesting observations of this engine include relatively low volumetric efficiencies of around $75 \%$. No prototypes of this engine type have been reported [54].

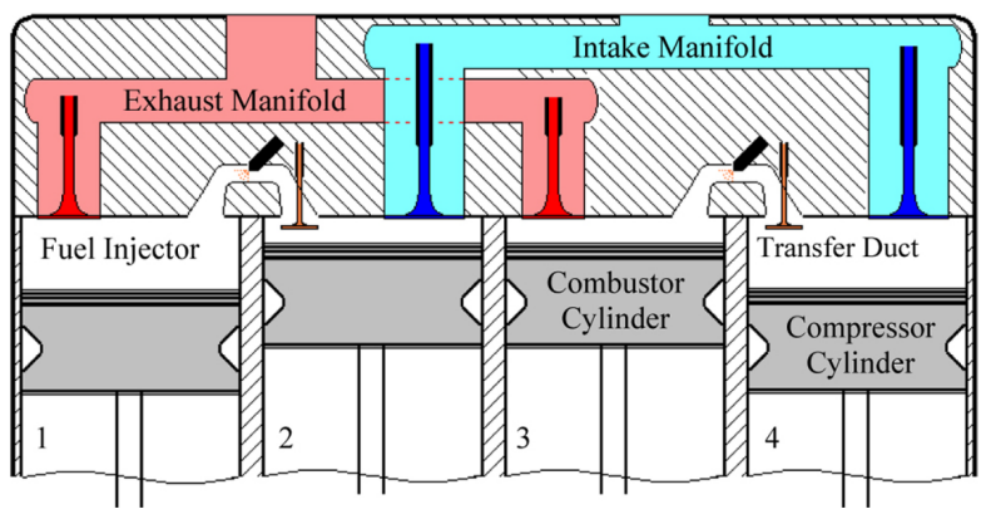

Figure 30 Schematic of a Four Cylinder Split Cycle Clean Combustion Engine, 2013 [54]

\section{Concluding Discussion}

Many split-cycle engine designs have emerged over the past century. The number of split-cycle patents has increased significantly over the past decade. Despite this, very few working physical examples are known to exist based on the open published literature. Significant prototype engines have been discussed in detail in this review, and to-date no production split-cycle engines are known to exist since the Ricardo Dolphin engine from 1906.

The two most recent complete split-cycle prototypes, the Scuderi Engine and the Tour Engine, are still undergoing development at the time of writing. Key design parameters for both of these engines include the crossover passage volume, the relative size of the expander cylinder to the compressor cylinder and the phase angle between the cylinders. Across all of the published literature there is no consensus regarding the optimum combination for these parameters. There is a trend towards trying to minimise the crossover passage volume across much of the literature; however, examples such as the IsoEngine and CryoPower engine feature a large crossover passage volume. The cylinder phase angle appears to carry significant importance, yet no two designs discussed use the same phase angle. The only apparent consistency is that the expander leads the compressor. Interestingly, the recent CryoPower engine design enables the compressor and expander to run at different speeds, thus the phase angle can vary considerably between cycles and is no longer an applicable design parameter. 
A summary of the various claims from the main sources is given in Table 1 . The main reason for promoting the use of a split-cycle configuration is to increase thermal efficiency and/or to reduce emissions, $\mathrm{NO}_{x}$ emissions in particular. Of significant concern is the belief that split-cycle engines are more efficient than conventional engines. The claim is consistently made across many sources, as well as among numerous patents. However, increased thermal efficiency is yet to be demonstrated by published test data. There appears to be a knowledge gap where fundamental analysis of the cycle itself is needed to establish why high thermal efficiencies are not being observed during experimental investigations. Reasons why increased thermal efficiency is not yet achieved could be due to practical trade-offs, or inherent architectural split-cycle engine design limitations. Successes of split-cycle development include demonstration of successful, rapid combustion in both an SI and Cl concept.

It is clear from the literature that there are some concerns regarding practical aspects of a split-cycle engine. Most notably:

1. Choked flow through the crossover valve into the expansion cylinder and short available valve opening times limit the amount of charge inducted. This could lead to low volumetric efficiencies, engine speed limitations and thus low power output engines. This would suggest that appropriate applications of split-cycle engines may be limited to stationary power generation applications;

2. Achieving combustion close to TDC as combustion timing must be traded off against the required time to induct charge. Late combustion leads to low indicated efficiency and could make combustion unstable;

3. The crossover valve into the expander experiences high accelerations and opens against large pressure differences meaning high forces are required to actuate the valve;

4. Thermal management challenges as the expansion cylinder experiences constant high temperatures.

An essential step forward for the split-cycle concept is to demonstrate the claimed high thermal efficiencies through physical test data. Alternatively, analysis can be undertaken to examine why high thermal efficiencies may not be achieved in practice and to guide the development of future engines/cycles that can overcome these shortcomings. 
Table 1 Summary of split-cycle claims

\begin{tabular}{|c|c|c|c|c|c|c|c|}
\hline & \multirow[b]{2}{*}{$\begin{array}{l}\text { Scuderi } \\
{[5][15]} \\
{[16][18]}\end{array}$} & \multicolumn{5}{|c|}{ Engine/ study } \\
\hline & & & $\begin{array}{l}\text { IsoEngine } \\
{[24][27]}\end{array}$ & $\begin{array}{c}\text { Single-Cyl } \\
\text { Combustor } \\
{[8]}\end{array}$ & $\begin{array}{l}\text { Tour } \\
\text { Engine } \\
{[30][31]}\end{array}$ & $\begin{array}{l}\text { Ruiz's } \\
\text { Study } \\
{[4][14]}\end{array}$ & $\begin{array}{c}\text { Caterpillar } \\
\text { SCCC } \\
{[53][54]}\end{array}$ \\
\hline \multirow{7}{*}{ 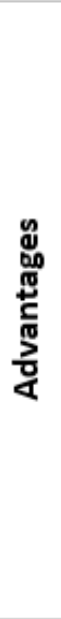 } & $\begin{array}{l}\text { Use of heat } \\
\text { recovery }\end{array}$ & & & & & & \\
\hline & Increased Efficiency & & & & & & \\
\hline & $\begin{array}{l}\text { Reduced Emissions, } \\
\mathrm{NO}_{\mathrm{x}}\end{array}$ & & & & & & \\
\hline & $\begin{array}{l}\text { Reduced Emissions, } \\
\text { Other }\end{array}$ & $x^{*}$ & & & & & \\
\hline & Faster Combustion & & & & & & \\
\hline & Knock resistant & & & & & & \\
\hline & Air-Hybridisation & & & & & & \\
\hline \multirow{5}{*}{ 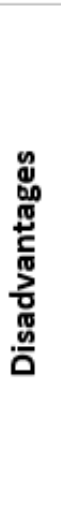 } & $\begin{array}{l}\text { Thermal } \\
\text { Management/ } \\
\text { Thermal Loading }\end{array}$ & & & & $\mathbf{x}$ & & \\
\hline & $\begin{array}{l}\text { Engine Speed } \\
\text { Limitations }\end{array}$ & & & $\checkmark$ & & & \\
\hline & $\begin{array}{l}\text { Low volumetric } \\
\text { efficiencies }\end{array}$ & & & & & & \\
\hline & Low Power/ MEP & & & & & & \\
\hline & $\begin{array}{l}\text { Valve actuation } \\
\text { difficulties }\end{array}$ & & & & & & \\
\hline
\end{tabular}

All claims are made in reference to conventional engines

$\checkmark$ - The given claim is said to be true, relating to the given engine or study

$\boldsymbol{X}$ - The opposite of the claim is said to be true, relating to the given engine

* - The given claim is supported by test data 


\section{References}

1. Cummins, C L. Internal Fire. Third edition. Oregon: Carnot Press, 2000.

2. Ricardo H R, inventor. Ricardo H R, assignee. Improvements in or relating to internal combustion engines. Patent GB 8743. 1906 April 11.

3. Black R B, inventor. Black R B, assignee. Split Cycle Internal Combustion Engine with Rotary Sleeve Valve. Patent US 2,799,258. 1957 July 16.

4. Ruiz, F. "Thermodynamic Modeling of the Two-Cylinder Regenerative Internal Combustion Engine," SAE Technical Paper 910346, 1991.

5. Phillips F, Gilbert I, Pirault J, and Megel M. "Scuderi Split Cycle Research Engine: Overview, Architecture and Operation," SAE Technical Paper 2011-01-0403, 2011.

6. Hirsch J, inventor. Improvement in Hot-Air engines. Patent US 155,087. 1874 September 15 .

7. Dong G, Morgan R, and Heikal M. "A novel split cycle internal combustion engine with integral waste heat recovery," Applied Energy, vol. 157, pp. 744-753, 2015.

8. Morgan R, Jackson N, Atkins A, Dong G, Heikal M, and Lenartowicz C. "the recuperated Split Cycle - Experimental Combustion Data from a Single Cylinder Test Rig," SAE Int. J. Engines 10(5):2017, doi:10.4271/2017-24-0169.

9. Webb S J, Webb R G, inventors. Webb S J, Webb R G, assignee. Gas-Engine. Patent US 1,062,999. 1913 May 27.

10. Thurston K W, Lundy J H, inventors. General Motors Corporation, assignee. Split Cylinder Engine and Method of Operation. Patent US 3,880,126. 1975 April 29.

11. Cataldo R S, inventor. General Motors Corporation, assignee. Quenched Combustion Separated Charge Internal Combustion Engine. Patent US 3,805,752. 1974 April 23.

12. Cataldo R S, inventor. General Motors Corporation, assignee. Dual Combustion Engine and Cycle. Patent US 3,808,818. 1974 May 7. 
13. Stang $\mathrm{J} \mathrm{H}$, inventor. Cummins Engine Company, Inc., assignee. Fluid Engine. Patent US 4,364,233. 1982 December 21.

14. Ruiz F, and Sepka S. "New Experiments and Computations on the Regenerative Engine," SAE Technical Paper 930063, 1993.

15. Scuderi C J, inventor. Scuderi Group LLC, assignee. Split Four Stroke Cycle Internal Combustion Engine. Patent US 6,543,225 B2. 2003 April 8.

16. Meldolesi R, Bailey G, Lacy C, Gilbert I, Pirault J, and Perkins A. "Scuderi Split Cycle Fast Acting Valvetrain: Architecture and Development," SAE Technical Paper 2011-01-0404, 2011.

17. Branyon D, and Simpson D. "Miller Cycle Application to the Scuderi Split Cycle Engine (by Downsizing the Compressor Cylinder)," SAE Technical Paper 2012$010419,2011$.

18. Meldolesi R, and Badain N. "Scuderi Split Cycle Engine: Air Hybrid Vehicle Powertrain Simulation Study," SAE Technical Paper 2012-01-1013, 2012.

19. Ramsey M. "Scuderi Engine Builds Digital Car That Gets 50 MPG," The Wall Street Journal, 18th May, 2011.

20. Scuderi Group, Inc About Us. [online]. Scuderi Group 2016. [viewed 03/05/2016] Available from: http://www.scuderigroup.com/about-us/.

21. Heywood, J B. Internal Combustion Engine Fundamentals. McGraw-Hill, 1988.

22. Kelly J, Scancs $P$, and Bloore $P$, "Specification and Design of a Switched Reluctance 48 V Belt Integrated Starter Generator (B-ISG) for Mild Hybrid Passenger Car Applications," SAE Technical Paper 2014-01-1890, 2014.

23. Coney M W, Linnemann C, and Abdallah H S, "A thermodynamic analysis of a novel high efficiency reciprocating internal combustion engine-the isoengine," Energy, 2004, Vol. 29(12-15), p.2585-2600.

24. Sugiura K, Kunimitsu M, and Coney M. "Isoengine Test Experience and Proposed Design Improvement," Proceedings of CIMAC conference, Vienna, Austria, May 2007. 
25. Coney M W, Stephenson P, Malmgren, A, Linnemann, C, Morgan R E, Richards R A, Huxley R, and Abdallah $\mathrm{H}$. "Development of A Reciprocating Compressor Using Water Injection To Achieve Quasi-Isothermal Compression," Proceedings of the $16^{\text {th }}$ International Compressor Engineering Conference, Purdue, Lafayette, Indiana, USA, Paper 1508, 2002.

26. Coney M, Linnemann C, Morgan R, Bancroft T, and Sammut R. "A Novel Internal Combustion Engine with Simultaneous Injection of Fuel and Pre-Compressed PreHeated Air," Proceedings ASME 2002 Fall Technical Conference, September 2002, New Orleans, USA, ICE-Vol. 39, pp. 67-77.

27. Coney M, Linnemann C, Sugiura K, and Goto T. "Isoengine Data Analysis and Future Design Options," Proceedings of the 24th CIMAC World Congress on Combustion Engine Technology, Kyoto, Japan, June 2004.

28. Coney M, Cross S, Linnemann C, Morgan R, and Wilson B. "Engineering Aspects of a Novel High Efficiency Reciprocating Internal Combustion Engine," Proceedings of International Joint Power Generation Conference, Phoeniz AZ USA, 2002.

29. Tour B H, Tour O, Tour G, inventors. Tour Engine, Inc., assignee. Crossover Valve in Double Piston Cycle Engine. Patent US 9,097,178 B2. 2014 November 20.

30. Tour B H, inventor. Tour Engine, Inc., assignee. Double Piston Cycle Engine. Patent US 7,516,723 B2. 2009 April 14.

31. Tour Engine, Inc. [online]. [viewed 03/05/2016]. Available from: http://www.tourengine.com/.

32. Clarke J M, inventor. Caterpillar Inc., assignee. In-Line Engines Having Residual Cycles and Method of Operation. Patent US 5,566,549. 1996 October 22.

33. Fiveland S B, inventor. Caterpillar Inc., assignee. Alternating Split Cycle Combustion Engine and Method. Patent US 8,904,981 B2. 2014 December 9.

34. Gehrke C R, inventor. Caterpillar Inc., assignee. Split-Cycle, Reactivity Controlled Compression Ignition Engine and Method. Patent US 9,038,582 B2. 2014 January 30. 
35. Boyer B A, Stockhausen W F, inventors. Ford Global Technologies LLC, assignee. Method of Supercharging an Engine. Patent US 6,382,193 B1. 2002 May 7.

36. Ricardo, Plc. Game changing Ricardo concept for high efficiency heavy duty diesel moves forward. Press release, 2013.

37. Jackson N, Atkins A, Eatwell J, and Morgan R. "An Alternative Thermodynamic Cycle for Reciprocating Piston Engines," Proceedings of 36th International Vienna Motor Symposium, Vienna, Austria, May 2015.

38. Jackson N S, Atkins A F, inventors. Ricardo Uk Limited, assignee. Split cycle reciprocating piston engine. Patent EP 2379861 B1. 2014 February 19.

39. Cummins, C L. Diesel's engine Vol One, from conception to 1918. Oregon: Carnot Press, 1993.

40. Andersson A, Jiang B, Lundgren S, Johansson S, Johansson B, inventors. Volvo Truck Corporation, assignee. An Internal Combustion Engine. Patent WO 2015090340 A1. 2015 June 25.

41. Andersson A, Jiang B, Lundgren S, inventors. Volvo Truck Corporation, assignee. An Internal Combustion Engine. Patent WO 2015144188 A1. 2015 October 01.

42. Durrett R P, Gopalakrishnan V, inventors. GM Global Technology Operations LLC, assignee. Internal Combustion Engine Utilizing Dual Compression and Dual Expansion Processes. Patent US 8,371,256 B2. 2013 Feb 12.

43. Mikame M, inventor. Honda Motor Co. Ltd., assignee. Internal combustion engine. Patent WO 2017104230 A1. 2017 June 22.

44. Schmitz G, inventor. Schmitz G, assignee. Five-stroke internal combustion engine. Patent US 6,553,977 B2. 2003 April 29.

45. Kéromnès A, Delaporte B, Schmitz G, and Le Moyne L. "Development and validation of a 5 stroke engine for range extenders application," Energy Conversion and Management, 2014, vol.83, pp. 259-267. 
46. Durrett, R. "A Pragmatic Approach to Maximizing Internal Combustion Engine Efficiency," Presented at SAE International High Efficiency IC Engine Symposium, Detroit MI, 8-9th April 2018.

47. Ruiz F. "A First Look into the Regenerative Engine," SAE Technical Paper 890473 , 1989.

48. Lam N, Turner M, Tunestal P, Andersson A, et al. "Double compression expansion engine concepts: a path to high efficiency," SAE Int. J. Engines 8(4):2015, doi:10.4271/2015-01-1260

49. Bhavani Shankar V, Lam N, Andersson A, and Johansson B. "Optimum Heat Release Rates for a Double Compression Expansion (DCEE) Engine," SAE Technical Paper 2017-01-0636, 2017, doi:10.4271/2017-01-0636.

50. Ruiz F. "Time-Dependent Analysis of the Regenerative Engine Cycle," SAE Technical Paper 900912, 1990.

51. Musu E, Rossi R, Gentili R, and Reitz R. "Clean Diesel Combustion by Means of the HCPC Concept," SAE Technical Paper 2010-01-1256, 2010.

52. Rossi R, Musu E, Frigo S, Gentili R, and Reitz R. "Simultaneous Reduction of Soot and NOX Emissions by Means of the HCPC Concept: Complying with the Heavy Duty EURO 6 Limits without Aftertreatment System," SAE Technical Paper 2013-240093, 2013.

53. Sud K, Cetinkunt S, and Fiveland S B. "Modeling and Validation of a Split Cycle Clean Combustion Diesel Engine Concept," Journal of Engineering for Gas Turbines and Power. 2013, Vol.135(8).

54. Sud K, Cetinkunt S, and Fiveland S B. "A Simulation Based Comprehensive Performance Evaluation of Cat ${ }^{\circledR}$ C4.4 Current Production Engine with its Split Cycle Clean Combustion Variant using a Validated One-Dimensional Modeling Methodology," SAE Technical Paper 2013-01-2434, 2013. 


\section{Abbreviations}

IC - Internal Combustion

SI - Spark Ignition

$\mathrm{Cl}$ - Compression Ignition

TDC - Top Dead Centre

BDC - Bottom Dead Centre

ATDC - After Top Dead Centre

BMEP - Brake Mean Effective Pressure

IMEP - Indicated Mean Effective Pressure

MEP - Mean Effective Pressure

LP - Low Pressure

HP - High Pressure

rpm - revolutions per minute

$\mathrm{NO}_{\mathrm{x}}$ - Nitrogen Oxides

PM - Particulate Matter

$\mathrm{CO}_{2}$ - Carbon Dioxide

CO - Carbon Monoxide

$\mathrm{HC}$ - Hydrocarbons

$\mathrm{LN}_{2}$ - Liquid Nitrogen

LNG - Liquified Natural Gas

ISG - Integrated Starter Generator

VVA - Variable Valve Actuation

AFR - Air/Fuel Ratio 